\title{
Molecular Mechanism of Stem Cell Differentiation into Adipocytes and Adipocyte Differentiation of Malignant Tumor
}

\author{
Kexin Zhang, ${ }^{1,2}$ Xudong Yang, ${ }^{3}$ Qi Zhao, ${ }^{1}$ Zugui Li, ${ }^{1,4}$ Fangmei Fu, ${ }^{1,4}$ Hao Zhang, ${ }^{1,4}$ \\ Minying Zheng, ${ }^{1}$ and Shiwu Zhang ${ }^{1}$ \\ ${ }^{1}$ Department of Pathology, Tianjin Union Medical Center, Tianjin, China \\ ${ }^{2}$ Nankai University School of Medicine, Nankai University, Tianjin, China \\ ${ }^{3}$ Tianjin Rehabilitation Center, Tianjin, China \\ ${ }^{4}$ Graduate School, Tianjin University of Traditional Chinese Medicine, Tianjin, China
}

Correspondence should be addressed to Shiwu Zhang; zhangshiwu666@aliyun.com

Received 30 April 2020; Revised 7 July 2020; Accepted 27 July 2020; Published 12 August 2020

Academic Editor: Hirotaka Suga

Copyright (C) 2020 Kexin Zhang et al. This is an open access article distributed under the Creative Commons Attribution License, which permits unrestricted use, distribution, and reproduction in any medium, provided the original work is properly cited.

Adipogenesis is the process through which preadipocytes differentiate into adipocytes. During this process, the preadipocytes cease to proliferate, begin to accumulate lipid droplets, and develop morphologic and biochemical characteristics of mature adipocytes. Mesenchymal stem cells (MSCs) are a type of adult stem cells known for their high plasticity and capacity to generate mesodermal and nonmesodermal tissues. Many mature cell types can be generated from MSCs, including adipocyte, osteocyte, and chondrocyte. The differentiation of stem cells into multiple mature phenotypes is at the basis for tissue regeneration and repair. Cancer stem cells (CSCs) play a very important role in tumor development and have the potential to differentiate into multiple cell lineages. Accumulating evidence has shown that cancer cells can be induced to differentiate into various benign cells, such as adipocytes, fibrocytes, osteoblast, by a variety of small molecular compounds, which may provide new strategies for cancer treatment. Recent studies have reported that tumor cells undergoing epithelial-to-mesenchymal transition can be induced to differentiate into adipocytes. In this review, molecular mechanisms, signal pathways, and the roles of various biological processes in adipose differentiation are summarized. Understanding the molecular mechanism of adipogenesis and adipose differentiation of cancer cells may contribute to cancer treatments that involve inducing differentiation into benign cells.

\section{Introduction}

Adipogenesis is the process through which mesenchymal stem cells (MSCs) commit to the adipose lineage and differentiate into adipocytes. During this process, preadipocytes cease to proliferate, begin to accumulate lipid droplets, and develop morphologic and biochemical characteristics of mature adipocytes, such as hormone-responsive lipogenesis and lipolytic programs. Currently, there are mainly two models of benign adipocyte differentiation in vitro. One is fibroid pluripotent stem cells, which can differentiate into not only adipocytes, but also muscle, cartilage, and other cells. There are two kinds of fibroid pluripotent stem cells: bone marrow and adipose mesenchymal stem cells. Another group is fibroblastic preadipocytes, which have a single direction of differentiation, namely, lipid differentiation, including
3T3-L1, and 3T3-F422A cells [1]. Cancer cells with tumor initiation ability, designated as cancer stem cells (CSCs), have the characteristics of tumorigenesis and the expression of specific stem cell markers, as well as the long-term selfrenewal, proliferation capacity, and adipose differentiation potential [2]. In addition to CSCs [2], cancer cells undergoing epithelial-mesenchymal transformation (EMT) have been reported to be induced to differentiate into adipocytes [3-5]. Lung cancer NCI-H446 cells can be induced to differentiate into neurons, adipocytes, and bone cells in vitro [6]. The adipogenesis differentiation treatment is promising in the $p 53$ gene deletion type of fibroblast-derived cancer [7]. Cancer cells with homologous recombination defects, such as ovarian and breast cancer cells with breast cancer susceptibility genes (BRCA) 1/2 mutations, can be induced to differentiate by poly ADP-ribose polymerase (PARP) 
inhibitors [2]. The nuclear receptor peroxisome proliferatoractivated receptor $\gamma(\operatorname{PPAR} \gamma)$ agonist (antidiabetic, thiazolidinedione drug) can induce growth arrest and adipogenic differentiation in human, mouse, and dog osteosarcoma cells [8]. Thyroid cancer cells expressing the PPAR $\gamma$ fusion protein (PPFP) can be induced to differentiate into adipocytes by pioglitazone [9]. Adipogenesis can be induced in welldifferentiated liposarcoma (WDLPS) and dedifferentiated liposarcoma (DDLPS) cells by dexamethasone, indomethacin, insulin, and 3-isobutyl-1-methyl xanthine (IBMX) [10].

In this review, we highlight some of the crucial transcription factors that induce adipogenesis both in MSCs and in CSCs, including the well-studied PPAR $\gamma$ and CCAAT enhancer-binding proteins (C/EBPs) [11], as well as other cell factors that have been recently shown to have an important role in adipocyte differentiation. We focus on understanding the complex regulatory mechanism of adipocyte differentiation that can contribute to the clinical treatment of human diseases, including those caused by obesity and adipocytes dysfunction, especially for the malignant tumor, which can be transdifferentiated into mature adipocytes.

\section{Adipocyte Differentiation}

Cell proliferation and differentiation are two opposing processes, and there is a transition between these two processes in the early stages of adipocyte differentiation. The interaction of cell cycle regulators and differentiation factors produces a cascade of events which ultimately results in the expression of adipocyte phenotype [7]. Adipogenesis has different stages. Each stage has a specific gene expression pattern [12]. In general, adipocyte differentiation of pluripotent stem cells is divided into two phases. The first phase, known as determination, involves the commitment of pluripotent stem cells to preadipocytes. The preadipocytes cannot be distinguished morphologically from their precursor cells, but also have lost the potential to differentiate into other cell types. In the second phase, which is known as terminal differentiation, the preadipocytes gradually acquire the characteristics of mature adipocytes and acquire physiological functions, including lipid transport and synthesis, insulin sensitivity, and the secretion of adipocyte-specific proteins [13].

The differentiation of precursor adipocytes is also divided into four stages: proliferation, mitotic cloning, early differentiation, and terminal differentiation [14]. After the precursors are inoculated into the cell culture plates, the cells grow exponentially until they converge. After reaching contact inhibition, the growth rate slows and gradually stagnates, and the proliferation of precursor adipocytes stops, which is very necessary for initiating the differentiation of precursor adipocytes. Adipocyte precursors exhibit transient mitosis, called "clonal expansion," a process that relies on the action of induced differentiation factors. Some preadipocyte cells (mouse cell lines 3T3-L1, 3T3-F442A) undergo one or two rounds of cell division prior to differentiation [15], whereas other cell lines (mouse C3H10T1/2) differentiating into adipocyte do not undergo mitosis clonal expansion [16]. Whether "mitotic clonal expansion" is required for adipose differentiation remains controversial. However, it is certain that some of the checkpoint proteins for mitosis regulate aspects of adipogenesis [7, 17]. When cells enter the terminal differentiation stage, the de novo synthesis of fatty acids increases significantly, the transcription factors and adipocyterelated genes work cooperatively to maintain precursor adipocyte differentiation into mature adipocytes containing large lipid droplets [1].

\section{Regulatory Pathways in Preadipocytes Commitment}

Adipocyte differentiation is a complex process in which gene expression is finely regulated. The most basic regulatory network of adipose differentiation has not been updated in recent years, but some factors and signaling pathways that do affect adipose differentiation have been continuously reported. Adipocyte differentiation is the result of the gene expression that determines the phenotype of adipocytes, which is a complex and delicate regulatory process (Figure 1).

3.1. Wnt Signal Pathway in Adipogenesis. Wnt signaling is important for adipocytes proliferation and differentiation both in vitro and in vivo [18]. The Wnt family of secreted glycoproteins functions through paracrine and autocrine mechanisms to influence cell fate and development. Wnt protein binding to frizzled receptors initiates signaling through $\beta$-catenin-dependent and -independent pathways [19]. Wnt signaling inhibits adipocyte differentiation in vitro by blocking the expression of PPAR $\gamma$ and $\mathrm{C} / \mathrm{EBP} \alpha$ [20]. Constitutive Wnt10b expression inhibits adipogenesis. Wnt10b is expressed in preadipocytes and stromal vascular cells, but not in adipocytes. In vivo, transgenic expression of Wnt10b in adipocytes results in a 50\% reduction in white adipose tissue mass and absent brown adipose tissue development [21]. Wnt10a and Wnt6 have also been identified as determinants of brown adipocyte development [22, 23]. Wnt5b is transiently induced during adipogenesis and promotes differentiation [24], indicating that preadipocytes integrate inputs from several competing Wnt signals.

3.2. The Hedgehog (HH) Signaling Pathway Mechanism. Three vertebrate $\mathrm{HH}$ ligands including sonic hedgehog $(\mathrm{SHH})$, Indian hedgehog $(\mathrm{IHH})$, and desert hedgehog $(\mathrm{DHH})$ have been identified and initiated a signaling cascade mediated by patched (Ptch-1 and Ptch-2) receptors [25, 26]. $\mathrm{HH}$ signaling had an inhibitory effect on adipogenesis in murine cells, such as C3H10T1/2, KS483, calvaria MSCs lines, and mouse adipose-derived stromal cells [27]. These cells were visualized by decreased cytoplasmic fat accumulation and the expression of adipocyte marker genes after $\mathrm{HH}$ signaling was inhibited [28]. Although it is generally agreed that $\mathrm{HH}$ expression has an inhibitory effect on preadipocyte differentiation, the mechanisms linking $\mathrm{HH}$ signaling and adipogenesis remain poorly defined [29].

3.3. ERK/MAPK/PPAR Signal Pathway. Extracellular-regulated protein kinase (ERK) is required in the proliferative phase of differentiation. ERK activity blockade in 3T3-L1 


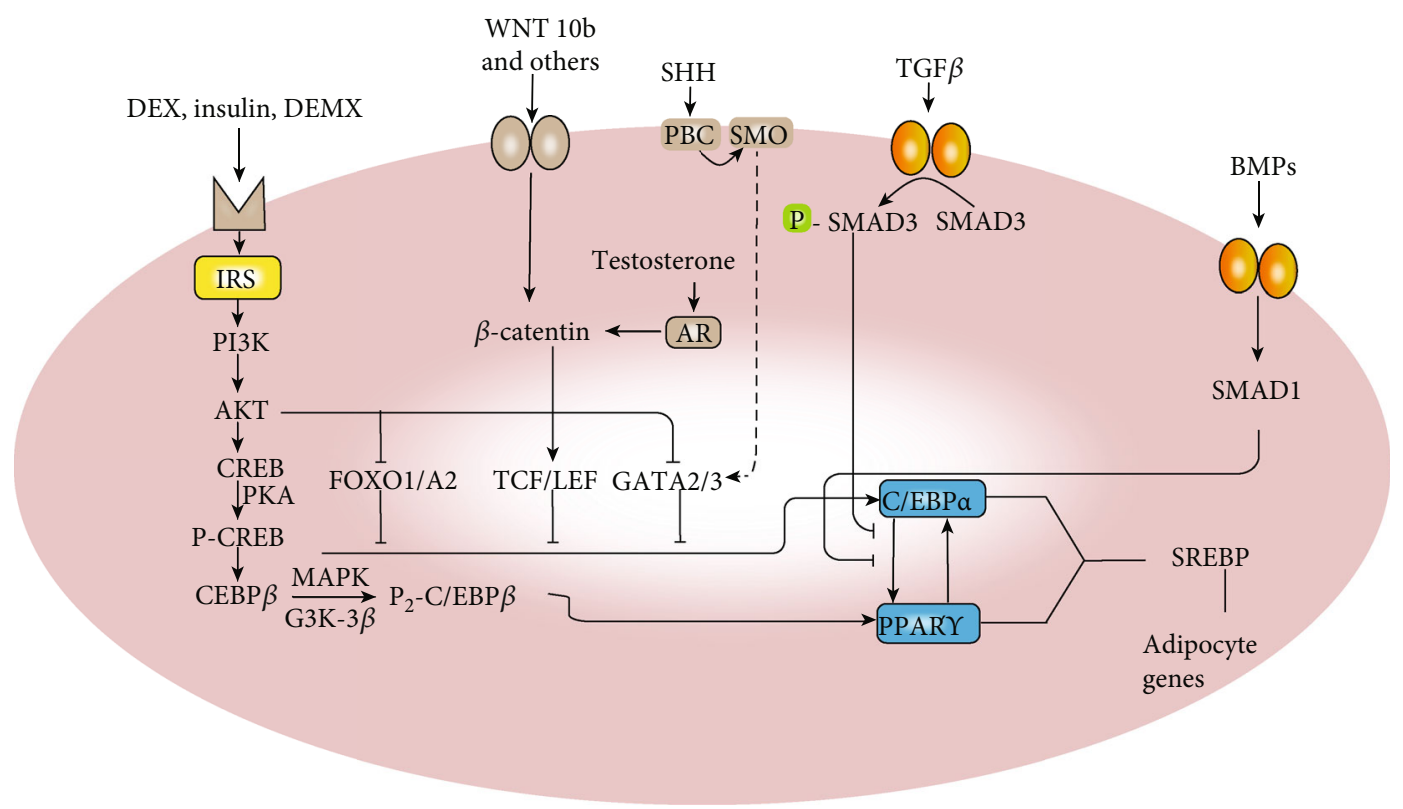

FIGURE 1: Regulation pathways in preadipocytes commitment. BMP and Wnt families are mediators of MSCs commitment to produce preadipocytes. Exposure of growth-arrested preadipocytes to differentiation inducers (IGF1, glucocorticoid, and cAMP) triggers DNA replication, leading to adipocyte gene expression due to a transcription factor cascade. The dotted line indicates an uncertain molecular regulatory mechanism.

cells and embryonic stem cells can inhibit adipogenesis. In the terminal differentiation phase, ERK1 activity leads to PPAR $\gamma$ phosphorylation, which inhibits adipocyte differentiation. This implies that ERK1 activity must be reduced after adipocyte proliferation so that differentiation can proceed. This reduction is mediated in part by mitogen-activated protein kinase (MAPK) phosphatase-1 (MKP1) [30, 31]. These extracellular and intracellular regulation factors cause adipocyte-specific gene expression and eventually lead to adipocyte formation.

\section{Adipocyte Differentiation Regulatory Proteins}

4.1. PPAR $\gamma$ and Adipocyte Differentiation. PPAR $\gamma$ is a member of the nuclear-receptor superfamily and is both necessary and sufficient for adipogenesis [32]. Forced expression of PPAR $\gamma$ is sufficient to induce adipocyte differentiation in fibroblasts [33]. Indeed, the proadipogenic C/EBPs and Krüppel-like factors (KLFs) have all been shown to induce at least one of the two PPAR $\gamma$ promoters. In contrast, antiadipogenic transcription factor GATA functioned in part by repressing PPAR $\gamma$ expression [34]. PPAR $\gamma$ itself has two isomers. The relative roles of PPAR $\gamma 1$ and PPAR $\gamma 2$ in adipogenesis remain an open question. PPAR $\gamma 2$ is mainly expressed in adipose tissue, while $\operatorname{PPAR} \gamma 1$ is expressed in many other tissues. Although both can promote adipocyte differentiation, PPAR $\gamma 2$ could do so effectively at very low ligand concentration compared with PPAR $\gamma 1$ [35]. The two protein isoforms are generated by alternative splicing and promoter usage, and both are induced during adipogenesis. PPAR $\gamma 1$ can also be expressed in cell types other than adipocytes. Ren et al. [36] used engineered zinc-finger proteins to inhibit the expression of the endogenous PPAR $\gamma 1$ and PPAR $\gamma 2$ promoters in 3T3-L1 cells. Ectopic expression of PPAR $\gamma 2$ promotes adipogenesis, whereas that of PPAR $\gamma 1$ does not. Zhang et al. reported that PPAR $\gamma 2$ deficiency impairs the development of adipose tissue and insulin sensitivity [37].

There are transcriptional cascades between adipocytes genes, including PPAR $\gamma$ and $\mathrm{C} / \mathrm{EBP} \alpha$ which are the core adipocyte differentiation regulators. In the early stage of adipocyte differentiation, the expression of $\mathrm{C} / \mathrm{EBP} \beta$ and $\mathrm{C} / \mathrm{EBP} \delta$ increase, which upregulates $\mathrm{C} / \mathrm{EBP} \alpha$ expression, further activate PPAR $\gamma$. PPAR $\gamma$ activating $\mathrm{C} / \mathrm{EBP} \alpha$ in turn results in a positive feedback. PPAR $\gamma$ binding with retinoic acid $\mathrm{X}$ receptor (RXR) forms different heterodimers. The various dimmers can combine with the PPAR $\gamma$ response element (PPRE) and initiate the transcription of downstream genes for differentiation into adipocytes [38].

C/EBPs participate in adipogenesis, and several C/EBP family members are expressed in adipocytes, including $\mathrm{C} / \mathrm{EBP} \alpha, \mathrm{C} / \mathrm{EBP} \beta, \mathrm{C} / \mathrm{EBP} \gamma, \mathrm{C} / \mathrm{EBP} \delta$, and C/EBP-homologous protein $(\mathrm{CHOP})$. The temporal expression of these factors during adipocyte differentiation triggers a cascade whereby early induction of $\mathrm{C} / \mathrm{EBP} \beta$ and $\mathrm{C} / \mathrm{EBP} \delta$ leads to $\mathrm{C} / \mathrm{EBP} \alpha$ expression. This notion is further supported by the sequential binding of these transcription factors to several adipocyte promoters during adipocyte differentiation. $\mathrm{C} / \mathrm{EBP} \beta$ is crucial for adipogenesis in immortalized preadipocyte lines. $\mathrm{C} / \mathrm{EBP} \beta$ and $\mathrm{C} / \mathrm{EBP} \delta$ promote adipogenesis at least in part by inducing $\mathrm{C} / \mathrm{EBP} \alpha$ and $\mathrm{PPAR} \gamma \cdot \mathrm{C} / \mathrm{EBP} \alpha$ induces many adipocyte genes directly and plays an important role in adipose tissue development. Once $\mathrm{C} / \mathrm{EBP} \alpha$ is expressed, its expression is maintained through autoactivation [39]. Despite the importance of C/EBPs in adipogenesis, 
these transcription factors clearly cannot function efficiently in the absence of PPAR $\gamma$. C/EBP $\beta$ cannot induce C/EBP $\alpha$ expression in the absence of PPAR $\gamma$, which is required to release histone deacetylase-1 (HDAC1) from the C/EBP $\alpha$ promoter [40]. Furthermore, ectopic $\mathrm{C} / \mathrm{EBP} \alpha$ expression cannot induce adipogenesis in PPAR $\gamma^{-/-}$fibroblasts [41]. However, $\mathrm{C} / \mathrm{EBP} \alpha$ also plays an important role in differentiated adipocytes. Overexpression of exogenous PPAR $y$ in $\mathrm{C} / \mathrm{EBP} \alpha$-deficient cells showed that, although $\mathrm{C} / \mathrm{EBP} \alpha$ is not required for lipid accumulation and the expression of many adipocyte genes, it is necessary for the acquisition of insulin sensitivity [42, 43] (Figure 2). Human fibroblasts with the ability to differentiate into adipocytes also do not undergo mitotic cloning amplification. However, PPAR $\gamma$ exogenous ligands need to be added to promote adipocyte differentiation. Therefore, it can be inferred that mitotic cloning expansion can produce endogenous ligands of PPAR $\gamma$ [7].

4.2. BMP and Transforming Growth Factor $\beta$ (TGF- $\beta$ ) in Adipocyte Differentiation. A variety of extracellular factors affect the preadipocyte commitment of stem cells, including bone morphogenetic protein (BMP) [44], transforming growth factor $\beta$ (TGF- $\beta$ ) [45], insulin/insulin-like growth factor 1 (IGF1) [46], tumor necrosis factor $\alpha$ and interleukin $1 \beta$ [47], matrix metalloproteinase 2 [48], fibroblast growth factor (FGF) 1 , and FGF2 [49]. BMP and TGF- $\beta$ have varied effects on the differentiation fate of mesenchymal cells [50]. The TGF- $\beta$ superfamily members, BMPs, and myostatin regulate the differentiation of many cell types, including adipocytes [51]. TGF- $\beta$ inhibitor can promote adipose differentiation of cancer cells with a mesenchymal phenotype in vitro, and transgenic overexpression of TGF- $\beta$ impairs adipocyte development [3]. Inhibition of adipogenesis could be obtained through blocking of endogenous TGF- $\beta$ with a dominant-negative TGF- $\beta$ receptor or drosophila mothers against decapentaplegic protein (SMAD) 3 inhibition. SMAD3 binds to C/EBPs and inhibits their transcriptional activity, including their ability to transactivate the PPAR $\gamma 2$ promoter [52, 53]. Exposure of multipotent mesenchymal cells to BMP4 commits these cells to the adipocyte lineage, allowing them to undergo adipose conversion [50]. The effects of BMP2 are more complex and depend on the presence of other signaling molecules. BMP2 alone has little effect on adipogenesis, and it interacts with other factors such as TGF- $\beta$ and insulin to stimulate adipogenesis of embryonic stem cells [54]. BMP2 stimulates adipogenesis of multipotent C3H10T1/2 cells at low concentrations and can contribute to chondrocyte and osteoblast development at higher concentrations [55].

4.3. KLFs in Adipocyte Differentiation. During adipocyte differentiation, some KLF family members are overexpressed, such as KLF4, KLF5, KLF9, and KLF15, while KLF16 expression is reduced [56, 57]. KLF15 is the first KLF family members, which were identified to be involved in adipocyte differentiation. Its expression increased significantly on the sixth day of 3T3-L1 adipocyte differentiation and peaked on the second day of adipocyte induction in MSCs and mouse embryonic fibroblasts. Inhibition of KLF15 by siRNA or mutation led to a decrease in $\operatorname{PPAR} \gamma, \operatorname{CEBP} \alpha$, fatty acidbinding protein 4 (FABP4), and glucose transporter 4 (GLUT4). However, overexpression of KLF15 in NIH3T3 cells was found to be associated with lipid accumulation as well as increases in PPAR $\gamma$ and FABP4 [58]. Mice with complete absence of KLF5 showed embryonal lethality, and mice with single-chromosome KLF5 knockout showed a significant reduction in white fat in adulthood, suggesting that KLF5 plays an important role in adipocyte differentiation. KLF5 can be activated by $\mathrm{C} / \mathrm{EBP} \beta$ or $\mathrm{C} / \mathrm{EBP} \delta$, which is involved in early adipocyte differentiation. KLF5 can be activated by $\mathrm{C} / \mathrm{EBP} \beta$ or $\mathrm{C} / \mathrm{EBP} \delta$, which is involved in early adipocyte differentiation. Direct binding of KLF5 to the PPAR $\gamma 2$ promoter in combination with $\mathrm{C} / \mathrm{EBP}$ induces PPAR $\gamma 2$ expression [59]. Transfection of KLF5 dominantnegative mutants in 3T3-L1 cells reduced lipid droplet accumulation and inhibited PPAR $\gamma$ and $\mathrm{C} / \mathrm{EBP} \alpha$ expression, whereas overexpression of wild KLF5 significantly promoted adipocyte differentiation, even without exogenous hormone stimulation. Similar to KLF5, KLF9 knockdown can inhibit the expression of a series of adipocyte differentiation genes, such as $\operatorname{PPAR} \gamma, \mathrm{C} / \mathrm{EBP} \alpha$, and $\mathrm{FABP} 4$, hence inhibiting adipocyte differentiation. However, KLF9 overexpression did not upregulate the expression of PPAR $\gamma$ and C/EBP $\alpha$ [60]. In addition, KLF4 can transactivate $\mathrm{C} / \mathrm{EBP} \beta$ by binding to the region of $1438-1134 \mathrm{~KB}$ upstream of the $\mathrm{C} / \mathrm{EBP} \beta$ promoter and promote lipid differentiation [61]. KLF6 can form a complex with histone deacetylase-3 (HDAC3), inhibiting preadipocyte factor-1 (Pref-1) expression and promoting lipid differentiation [62]. KLF2 is highly expressed in adipose progenitors, and its expression decreases during the process of lipid differentiation. Overexpressed KLF2 can bind to the CACCC region of PPAR $\gamma 2$ proximal promoter and inhibit lipid differentiation as well as the expression of PPAR $\gamma$, $\mathrm{C} / \mathrm{EBP} \alpha$, and sterol-regulated element-binding proteins (SREBP) by inhibiting the promoter activity [63]. RNA sequence analysis showed that KLFl6 expression was decreased on the first day of adipocyte differentiation of 3T3-L1 cells. Adipocyte differentiation was promoted by KLF16 knockdown but was inhibited by KLF16 overexpression via inhibition of PPAR $\gamma$ promoter activity [64]. In addition, KLF3 and KLF7 were also found to play a negative regulatory role in adipocyte differentiation $[65,66]$.

4.4. Signal Transducers and Activators of Transcription (STATs) and Adipocyte Differentiation. The activated STAT protein enters the nucleus as a dimer and binds to the target gene to regulate gene transcription. In the adipocyte differentiation of mouse 3T3-L1 cells, the expression of STAT1 and STAT5 was significantly increased, while that of STAT3 and STAT6 was not significantly changed [67]. In the adipocyte differentiation of human subcutaneous adipose precursor cells, STAT1 expression was significantly decreased [68], while the expression of STAT3 and STAT5 was increased and STAT6 expression was unchanged [69]. The role of STAT1 in adipocyte differentiation is not clear, because its expression trend in humans and mice differs during the adipocyte differentiation process. Early adipocyte differentiation of 3T3-L1 cells was inhibited by STAT1 


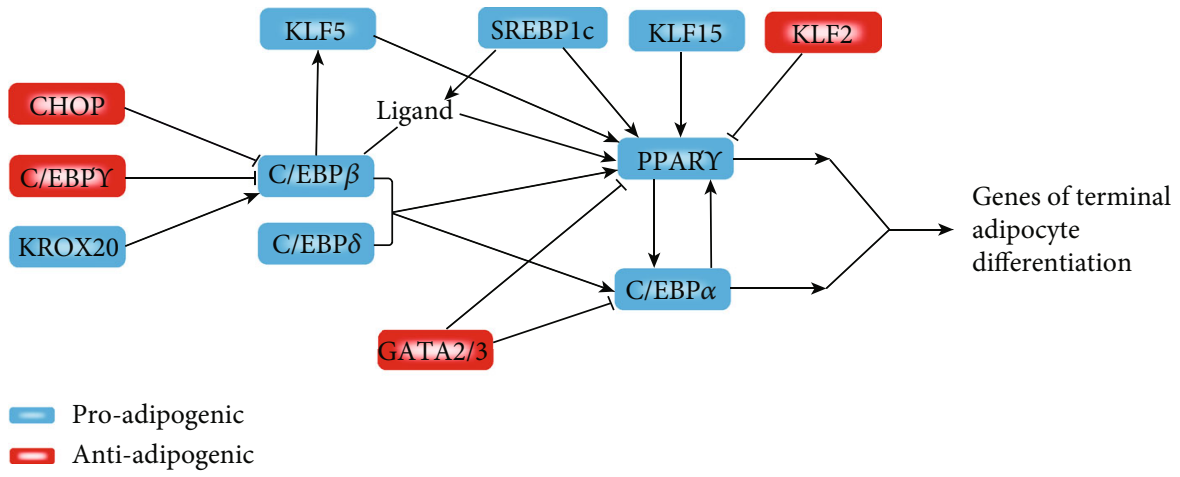

FIgURE 2: A cascade of transcription factors that regulate adipogenesis. PPAR $\gamma$ is one of the key transcription factors in adipogenesis and the core of the transcriptional cascade that regulates adipogenesis. PPAR $\gamma$ expression is regulated by several proadipogenic (blue) and antiadipogenic (red) factors. $\mathrm{C} / \mathrm{EBP} \alpha$ is regulated through a series of inhibitory protein-protein interactions. Some transcription factor families include several members that participate in adipogenesis, such as the KLFs. Black lines indicate effects on gene expression; violet lines represent effects on protein activity.

agonist interferon $\gamma$. Loss of STAT1 in 3T3-L1 cells can rescue the inhibition of adipocyte differentiation caused by prostaglandin factor $2 \alpha[70]$. Other studies have found that STAT1 is required for adipose differentiation, and STAT1 overexpression in $\mathrm{C} 3 \mathrm{H} 10 \mathrm{~T} 1 / 2$ cells can prevent the inhibition of lipid differentiation caused by B-cell lymphoma- 6 knockdown [71]. There was no abnormal adipose tissue in STAT1 knockout mice [72]. STAT3 not only affects the proliferation of 3T3-L1 cells but also coregulates their adipocyte differentiation with high mobility group protein 2 [73]. The FABP4 promoter was used to specifically knock out STAT3 in the adipose tissue of mice, and the results showed that mice weight significantly increased and the adipocyte quantity increased compared with the wild-type mice [74]. STAT5A and STAT5B have different effects on adipocyte differentiation. Abnormal adipose tissue was found in the mice with STAT5A or STAT5B knockout or double knockout, and the amount of adipose tissue was only one-fifth of the original adipose tissue in mice without knockdown [75].

4.5. Histone Modification in Adipocyte Differentiation. Histone deacetylase sirtuin (SIRT) 1 plays an important role in biological processes such as stress tolerance, energy metabolism, and cell differentiation [76]. During the adipocyte differentiation of C3H101/2 cells, SIRT1 expression decreased [77]. Overexpression of SIRT1 activated the Wnt signal, which caused the deacetylation of $\beta$-catenin. The accumulation of $\beta$-catenin in the nucleus could inhibit adipocyte differentiation. SIRT1 knockdown resulted in increased acetylation of the histones $\mathrm{H} 3-\mathrm{K} 9$ and $\mathrm{H} 4-\mathrm{K} 16$ in the secreted frizzled-related protein (sFRP) 1 and sFRP2 promoters, thereby promoting transcription of these genes and promoting lipid differentiation [78]. Forkhead box protein $\mathrm{O}$ (FOXO) 1 is a member of the transcription factor FOXO family. It can recruit cyclic AMP response element-binding protein (CBP)/histone acetyltransferase p300 to initiate an acetylation. The acetylated FOXO1 can be phosphorylated by phosphorylated protein kinase B (PKB/AKT). The phosphorylation of FOXO1 by AKT inhibits the transcriptional activation of FOXO1. The acetylation of FOXO1 lost the ability of DNA-binding affinity and promoted its shuttling from nuclei to cytoplasm [79]. SIRT1 and SIRT2 can deacetylate and active FOXO1. Activated FOXO1 (nonphosphorylated nuclear FOXO1) in the nucleus binds to the promoters of target genes encoding p21, p27, and PPAR $\gamma$, and initiates subsequent transcriptions [80]. SIRT2 inhibits the acetylation and phosphorylation of FOXO1, thereby induces the accumulation of activated FOXO1 in the nucleus. Activated FOXO1 could inhibit adipogenesis via PPAR $\gamma$ [81-84]. Lysinespecific histone demethylase 1 (LSD1) expression increased during the adipocyte differentiation of 3T3-L1 cells. LSD1 could reduce the dimethylation levels of histone H3K9 and $\mathrm{H} 3 \mathrm{~K} 4$ in the $\mathrm{C} / \mathrm{EBP} \alpha$ promoter region, thereby promoting adipocyte differentiation [85]. SET domain-containing 8 (SETD8) catalyzed the monomethylation of H4K20 and promoted PPAR $\gamma$ expression. The activation of $\operatorname{PPAR} \gamma \operatorname{tran}-$ scriptional activity leads to the induction of monomethylated H4K20 and modification of PPAR $\gamma$ and its targets, thereby promoting adipogenesis [86]. Enhancer of zeste homolog 2 (EZH2) is a methyltransferase and can bind methyl groups to histone $\mathrm{H} 3 \mathrm{~K} 27$, which is also necessary for lipid differentiation. The absence of EZH2 in brown fat precursors results in reduced levels of the Wnt promoter histone H3K27me3, which is also saved by the ectopic EZH2 expression or the use of a Wnt/ $\beta$-catenin signal inhibitor [87]. In addition, histone demethylases such as lysine-specific histone demethylase (LSD/KDM) 4, KDM6, and histone lysine demethylase PHF2 are also involved in adipose differentiation, and KDM2B inhibits transcription factor activator protein $2 \alpha$ promoter via $\mathrm{H} 3 \mathrm{~K} 4 \mathrm{me} 3$ and $\mathrm{H} 3 \mathrm{~K} 36 \mathrm{me} 2$ [88].

\section{Role of microRNA and Long Noncoding RNA in Adipogenesis}

microRNA (miR) can bind and cut target genes or inhibit target gene translation. Endogenous siRNA can be produced by the action of Dicer enzyme and bind to a specific protein to change its cellular location [89]. Many kinds of miRs are involved in regulating adipocyte differentiation. The 
expression of miR-143 increased during the differentiation of adipose progenitor cells. Overexpression of miR-143 promoted gene expression involved in adipose differentiation and triglyceride accumulation. Inhibition of miR-143 prevented the adipose differentiation of human fat progenitor cells $[90,91]$. Additionally, miR-8 promotes adipocyte differentiation by inhibiting Wnt signaling [92]. Moreover, miR17-92, miR-103, miR-21, miR-519d, miR-210, miR-30, miR-204/211, and miR-375 also play a certain role in promoting adipocyte differentiation, while miR-130, miR-448, and let-7y inhibit lipid differentiation [93, 94]. In addition to miRs, long noncoding RNA (LncRNA) is a type of noncoding RNA and is important during epigenetic regulation and can form a double-stranded RNA complex with mRNA causes protein transcription. Lnc-u90926 inhibits adipocyte differentiation by inhibiting the transactivation of PPAR $\gamma 2$ [95]. As a novel LncRNA, HOXA-AS3 expression increased during the adipose differentiation of MSCs, and HOXAAS3 silencing reduced the marker gene of adipose differentiation and inhibited the adipose differentiation [96]. Zhu et al. [97] reported that HOXA-AS3 interacted with EZH2 to regulate lineage commitment of MSCs. HOXA -AS3 can regulate the trimethylation level of $\mathrm{H} 3 \mathrm{~K} 27$ in the Runx2 promoter region by binding to EZH2. Therefore, HOXAAS3 is considered to be an epigenetic switch regulating MSCs lineage specificity [98]. Adipocyte differentiation-associated LncRNA can act as a competitive endogenous RNA of miR204 in the process of lipid differentiation, thereby promoting the expression of SIRT1, the target gene of miR-204, and thus inhibiting lipid differentiation [99]. The LncRNA NEAT1 can also regulate adipocyte differentiation under the influence of miRNA140 [100]. Other LncRNA including LncRNA Blnc1 and Plnc 1 are also involved in regulating adipocyte differentiation [101, 102].

\section{Other Biochemical Response Involved in Adipocyte Differentiation}

6.1. Unfolded Protein Responses in Adipocyte Differentiation. In the endoplasmic reticulum of eukaryotes, unfolded protein response involves three proteins: inositol-requiring enzyme $1 \alpha$, double-stranded RNA-dependent protein kinase-like ER kinase, and activating transcription factor (ATF) $6 \alpha$ [103]. Knockdown of ATF6 $\alpha$ affects the expression of adipocytes genes and inhibits C3H10T1/2 adipocyte differentiation [104]. The inhibitory effect of berberine on adipocyte differentiation of 3T3-L1 cells is also due to induced CHOP and decorin 2 expressions, and this inhibitory effect is ameliorated by CHOP knockout [105]. In the adipocyte differentiation process of 3T3-L1 cells, increases in PPAR $\gamma$ and $\mathrm{C} / \mathrm{EBP} \alpha$ as markers of adipocyte differentiation were accompanied by an increase in the corresponding protein expressions of phosphorylated Eukaryotic translation initiation factor (EIF) $2 \alpha$, phosphorylated endoribonuclease IRE1 $\alpha$, ATF4, CHOP, and other unfolded protein responses. Endoplasmic reticulum stress inducer or hypoxic endoplasmic reticulum stress can inhibit adipocyte differentiation. Additionally, EIF2 $\alpha$ mutation results in continuous activation or overexpression of CHOP, which also inhibits adipo- cyte differentiation [106]. After the initiation of adipose differentiation, numerous differentiation-associated proteins are synthesized. Exogenous endoplasmic reticulum stress inducers can lead to excessive endoplasmic reticulum response, which in turn affects the synthesis of proteins related to differentiation and inhibits adipocyte formation (Figure 3).

6.2. Role of Oxidative Stress in Adipogenesis. During the directional differentiation of MSCs, mitochondrial complex I and III, and NADPH oxidase NOX4 are the main sources of oxygen species (ROS) production. Currently, it is believed that ROS affects not only the cell cycle and apoptosis but also differentiation through influencing the signaling pathways including the Wnt, $\mathrm{HH}$, and FOXO signaling cascade during MSCs differentiation [107]. The differentiation ability of stem cells is determined by the arrangement of perinuclear mitochondria, which specifically manifests as low ATP/cell contents and a high rate of oxygen consumption. The lack of these characteristics indicates stem cell differentiation [108]. Adipocyte differentiation is a highly dependent ROS activation factor related to mitosis and cell maturation [109]. Schroder et al. found that exogenous $\mathrm{H}_{2} \mathrm{O}_{2}$ could stimulate adipocyte differentiation of mouse 3T3-L1 cells and human adipocyte progenitor cells in the absence of insulin. $\mathrm{H}_{2} \mathrm{O}_{2}$ regulates adipocyte differentiation of 3T3-L1 cells in a dose-dependent manner. High doses of $\mathrm{H}_{2} \mathrm{O}_{2}(1,10$, and $30 \mu \mathrm{M})$ promote adipocyte differentiation [110, 111]. Tormos et al. found that ROS synthesis increased in human MSCs at the early stage of adipose differentiation, and targeted antioxidants could inhibit lipid differentiation. By knocking down Rieske iron-sulfur protein and ubiquinonebinding protein, ROS produced by mitochondrial complex III was found to be necessary in initiating adipose differentiation [112]. However, other studies have shown that the expression levels of adiponectin and PPAR $\gamma$ were decreased by using $\mathrm{H}_{2} \mathrm{O}_{2}(0.1-0.5 \mathrm{mM})$ in 3T3-L1 cells [113]. Free radical nitric oxide (NO) also promotes lipid differentiation, because treatment with $\mathrm{NO}$ inducer hydroxylamine or $\mathrm{NO}$ synthase (NOS) substrate arginine can significantly induce adipose differentiation of rat adipose progenitor cells. NOS induced adipose differentiation mainly via eNOS rather than iNOS [114]. ROS can induce adipose differentiation primarily by inhibiting Wnt, FOXO, and $\mathrm{HH}$ signaling pathways that inhibit lipid differentiation.

6.3. Autophagy in Adipocyte Differentiation. The increase in autophagosomes during lipid differentiation indicates that autophagy may play an important role in lipid differentiation [115]. Baerga et al. confirmed that the adipocyte differentiation efficiency was significantly inhibited in mouse embryonic fibroblasts lacking autophagy-related gene (Atg) 5, a gene encoding an essential protein required for autophagy [116]. Knockdown of Atg5 in 3T3-L1 cells promotes proteasome-dependent degradation of $\operatorname{PPAR} \gamma 2$, thereby inhibiting adipocyte differentiation [117]. Zhang reported that autophagy-related gene $7($ Atg7) is also crucial for adipose development. Atg7-deficient mice were slim and only had $20 \%$ of white fat compared to wild-type mice, and the 


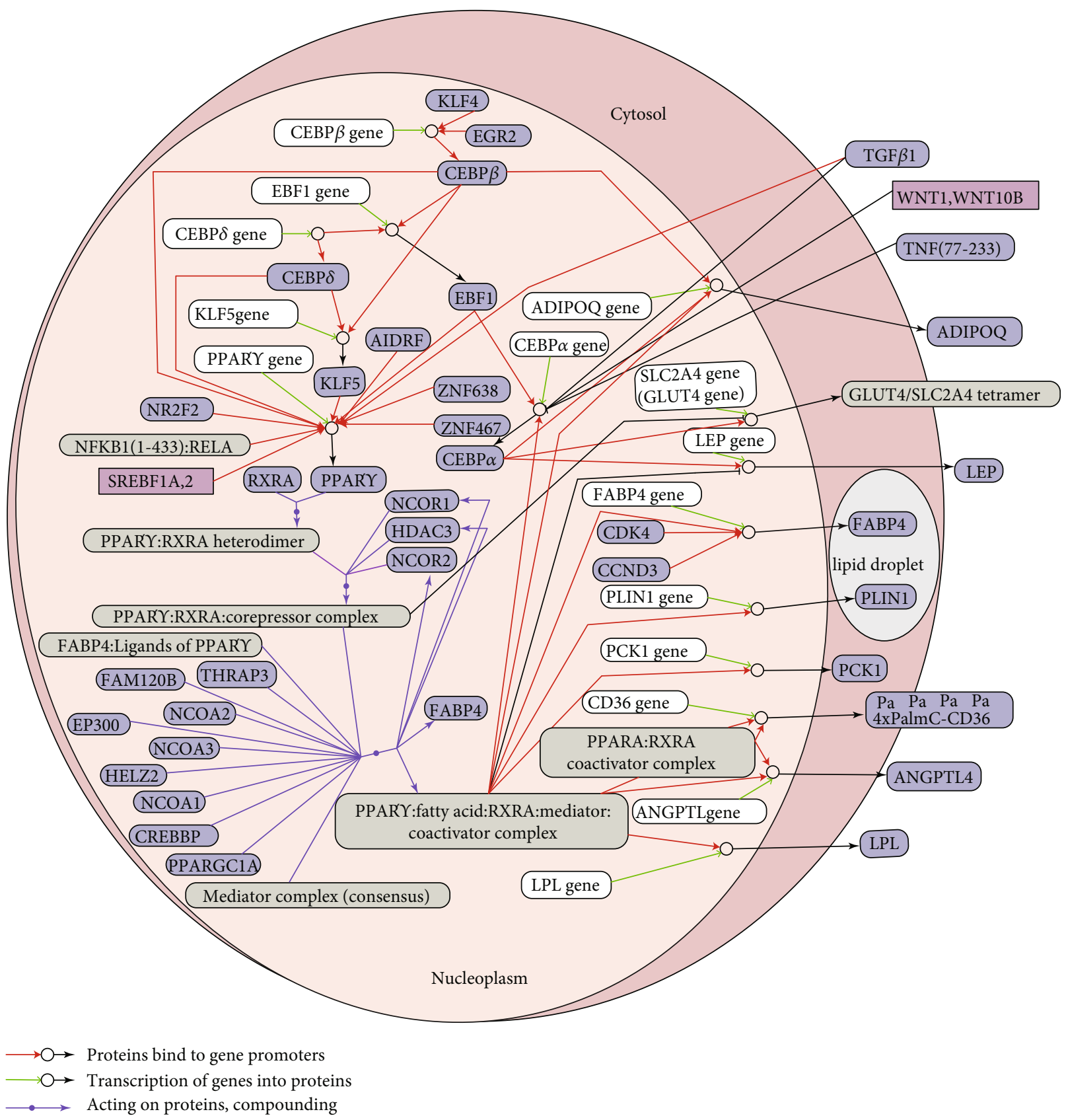

FIgURE 3: Regulation of adipocyte differentiation. A regulatory loop exists between PPAR $\gamma$ and CEBP activation. Transcription factor Coe $(\mathrm{EBF})$ activates $\operatorname{CEBP} \alpha, \operatorname{CEBP} \alpha$ activates $\mathrm{EBF} 1$, and $\mathrm{EBF} 1$ activates $\operatorname{PPAR} \gamma \cdot \operatorname{CEBP} \beta$ and $\operatorname{CEBP} \delta$ act directly on the PPAR $\gamma$ gene by binding its promoter and activating transcription. $\mathrm{CEBP} \alpha, \mathrm{CEBP} \beta$, and CEBP $\delta$ can activate the EBF1 gene and KLF5. The EBF1 and KLF5 proteins in turn bind the promoter of PPAR $\gamma$, which becomes activated. Other hormones, such as insulin, can affect the expression of PPAR $\gamma$ and other transcription factors, such as SREBP1c. PPAR $\gamma$ can form a heterodimer with the RXR $\alpha$. In the absence of activating ligands, the PPAR $\gamma$-RXR $\alpha$ complex recruits transcription repressors, such as nuclear receptor corepressor (NCoR) 2, NCoR1, and HDAC3. Upon binding with activating ligands, PPAR $\gamma$ causes a rearrangement of adjacent factors. Corepressors such as NCoR2 are lost, and coactivators such as Transcription intermediary factor TIF2, CBP, and p300 are recruited, which can result in the expression of Cyclic AMP-responsive element-binding protein (CREB) followed by PPAR $\gamma$. PPAR $\gamma$ expression initiates the expression of downstream genes, including angiopoietin-related protein PGAR, Perilipin, FABP4, CEBP $\alpha$, fatty acid transport-related proteins, carbohydrate metabolismrelated proteins, and energy homeostasis-related proteins.

lipid metabolism and hormone-induced lipolysis in the adipocytes were altered [118]. Autophagy related gene Atg $4 \mathrm{~b}$ is activated by C/EBP $\beta$ in the process of lipid differentiation, and autophagy activation is necessary for the degradation of Klf2 and Klf3, two negative regulators of lipid differentiation. These results showed that adipose differentiation and autophagy are mutually complementary [119]. In 3T3-L1 cells, autophagy was inhibited by aspartate ammonia or 3- 
methyladenine at different lipid induction periods $(0-2,2-4$, $4-6$, and 6-8 days), and only autophagy inhibition at $0-2$ days hindered the formation of lipid droplets and the expression of lipid marker genes, indicating that autophagy was very important in the early stage of lipid differentiation [120]. Recent studies showed that LC3 is overexpressed in 3T3-L1 cells, further demonstrating the important role of autophagy in lipid differentiation [121].

6.4. Role of Alternative Splicing in Adipogenesis. Selective splicing is influenced by splicing regulators, which regulate adipocyte differentiation by regulating the selective splicing of genes specific to this process. Lipin 1 is an important regulator in the process of adipocyte differentiation and includes two isomers, Lipin $1 \alpha$ and $\operatorname{Lipin} 1 \beta$, which have different effects. High expression of Lipin $1 \alpha$ promotes adipocyte differentiation, while that of Lipin $1 \beta$ promotes lipid droplet formation [122]. In Sam68-deficient mice, the fifth intron of serine/threonine-protein kinase mTOR was retained, resulting in unstable and rapid mTOR degradation and inhibition of adipocyte differentiation [123]. Furthermore, there are four isomers of Pref-1, Pref-1a and Pref-1b can inhibit adipocyte differentiation of 3T3-L1, while Pref-1c and Pref-1d have no effect on this process [124].

6.5. Cytoskeletal Remodeling in Adipocyte Differentiation. During adipocyte differentiation from stem cells, morphological changes to cells due to remodeling of the actin cytoskeleton are the hallmark of differentiation. McBeath et al. showed that cell shape was associated with differentiation of human MSCs to adipocytes or osteoblasts. Flattened and spread cells underwent osteogenesis, while unspread, round cells became adipocytes. They demonstrated that mesenchymal cells mainly from mesoderm cells were more prone to adipocyte differentiation, while pinacocytes were more prone to osteogenic differentiation. Disruption of actin by cytochalasin $\mathrm{D}$ can significantly promote adipocyte differentiation [125]. The increase in the monomer G-actin interacts with megakaryoblastic leukemia 1 and inhibits its nuclear translocation, thereby promoting PPAR $\gamma$ expression during adipocyte differentiation [126], while the mTORC2 signal and RhoA-ROCK mediate cytoskeletal remodeling and MSCs lineage selection [127]. During adipocyte differentiation, the formation of cortical actin structures starts with the accumulation of filamentous actin near the cell membrane. The cortical assembly and nucleation of actin are controlled by the actin-related protein 2/3 (Arp2/3) complex. Yang et al. found that Arp2/3 knockdown seriously inhibited adipocyte differentiation of cells, and the cortical actin cytoskeleton was very important for the secretion of GLUT4 particles into cells as well as insulin signal transduction [128].

\section{Adipose Differentiation Induction of Malignant Tumor Cells}

Tumors are considered to be heterogeneous ecosystems composed of a variety of tumor cell subsets and stromal cells. Cancer cells are typically characterized by uncontrolled proliferation and disorders of differentiation. The long-term self- renewal, proliferation capacity, and differentiation potential of CSCs are considered to be the major determinants of tumor recurrence, treatment failure and metastasis, and chemotherapy-resistant [129]. Only one subset of tumor cells can drive tumorigenesis and initiate the formation of heterogeneous tumors. It is important to note that any cell in the tumor may gain or lose its initiation-ability due to tumor microenvironment or therapeutic interventions. Therefore, CSCs should be considered as a state cell rather than a static subpopulation of cancer cells [130, 131]. Adipose differentiation of human MSCs could be induced by using a complex stimulus which includes dexamethasone, 3-isobutyl-1-methylxanthine, indomethacin, and insulin (a classical cocktail) [132]. Our previous study has shown that polyploid giant cancer cells (PGCCs) had the properties of CSCs and can be induced into adipose in vitro and in vivo [133].

7.1. Malignant Tumor Cells Can Be Induced Adipocytes. WDLPS and dedifferentiated DDLPS are the most common types of liposarcoma. WDLPS/DDLPS cells can be induced to differentiate into adipocytes by dexamethasone, indomethacin, insulin, and IBMX. In vitro experiments have shown that these four compounds induce adipogenesis by upregulation of transcription and translation of genes involved in maintaining cancer cell stemness and adipogenic differentiation, which might be used in the clinical treatment of DDLPS patients in the future [10]. In vivo, the induction of adipogenesis inhibited the tumorigenic ability of DDLPS. The tumor suppressor protein $p 53$ is the negative regulator of adipocyte formation and the positive regulator of insulin sensitivity [134]. In theory, adipocyte-inducing agent can result in the least partial differentiation of tumor cells, reducing their malignant phenotype in $p 53$ deficient tumors. The adipogenic differentiation potential is promising in the treatment of cancer cell-derived from $p 53$ deletion fibroblast.

7.2. Adipocyte Differentiation of CSCs. CSCs are a very small population of cancer cells that exist in tumor tissue and closely related to the occurrence, development, metastasis, recurrence, and drug resistance of malignant tumors [135]. Adipocytes can derive not only from preadipocytes and pluripotent MSCs but also CSCs. Our previous study has shown that cobalt chloride $\left(\mathrm{CoCl}_{2}\right)$ was used to treat different cancer cell lines and daughter cells derived from PGCCs gained a mesenchymal phenotype [133]. When cultured with adipogenesis medium, PGCCs can differentiate into adipocytes [133].

7.3. Molecular Mechanism of CSCs Differentiating into Adipose. The molecular mechanism of adipose differentiation of CSCs is similar to that of MSCs. PPAR $\gamma$ activation is the key to adipocyte differentiation of CSCs in vivo. The phosphorylation of FOXO1 by AKT inhibited the transcriptional activation of FOXO1 and activated FOXO1 could inhibit adipogenesis via PPAR $\gamma$ [80]. Activated AKT1 after phosphorylation was of great significance to promote adipogenesis via mTORC2-AKT1-FOXC2 signal pathway [136]. $\mathrm{PI} 3 \mathrm{~K} / \mathrm{AKT}$ plays an important role in maintaining the stemness of various CSCs. The expression of OCT4 and Nanog in 
breast CSCs depended on the PI3K/AKT pathway [137]. Cytochrome c oxidase 2 inducing the formation of CSCs in breast cancer was involved in the activation of PI3K and AKT [138]. Activating PI3K/AKT signal pathway promoted the initiation of liver CSCs [139]. Inhibition of PI3K/Akt/mTOR pathway suppressed the stemness of colon CSCs [140]. AKT signal pathway plays an important role both in the formation and differentiation of CSCs. The nuclear oncoprotein Myc was a pivotal regulator in cell cycle regulation, proliferation, differentiation, and apoptosis [141, 142]. Deregulated Myc expression was incompatible with terminal differentiation in a variety of cell types, including adipocytes [141].

PARP is a DNA repair enzyme and plays an important role in DNA damage repair and apoptosis. PARP family members are associated with CSC biology and its inhibition, including the development, neurogenesis, and adipogenesis of stem cells. PARP1 and PARP2 are crucial for adipocyte differentiation and the regulation of lipid accumulation [143]. PARP1 can keep the preadipocytes in the stationary phase of growth and inhibits the formation of adipocytes [144]. PARP-1 can mediate poly-ADP-ribosylation (PARylation) of $\mathrm{CEBP} \beta$ and PARylation is a posttranslational modification of proteins mediated by PARP family members. $\mathrm{CEBP} \beta$ is the crucial transcription factor in adipogenesis. The PARylation of CEBP $\beta$ changes its DNA binding and transcriptional activities and thus inhibits the adipocyte differentiation of stem cells. Depletion or chemical inhibition of PARP-1, or mutation of the PARylation sites on $\mathrm{C} / \mathrm{EBP} \beta$, promotes early adipogenesis [144]. PPAR $\gamma$ binding with RXR forms different heterodimers plays a central role in white adipose tissue (WAT) differentiation and function, regulating the expression of key WAT proteins [145]. PARP-2 is a member of the PPAR $\gamma / \mathrm{RXR}$ transcription machinery and a novel cofactor of PPAR activity. PARP-2 overexpression enhanced the basal activity of $\operatorname{PPAR} \gamma$ and PARP-2(-/-) mouse embryonic fibroblasts failed to differentiate into adipocytes. In transient transfection assays, PARP-2 siRNA decreases basal activity and liganddependent activation of PPAR $\gamma$. Chromatin immunoprecipitation has shown a DNA-dependent interaction of PARP-2 and PPAR $\gamma /$ RXR heterodimer [145].

7.4. Differentiation Therapy of Malignant Tumor. CSC-specific phenotypes and mechanisms indicate that CSCs may contribute to the failure of existing therapies to consistently eradicate malignant tumors [146]. Differentiation of primitive cells within a malignancy may lead to tumor degeneration and increased susceptibility to conventional cytotoxic anticancer therapies [147]. Differentiation therapy has been recognized for a long time, and potential strategies are that induce quiescent CSCs to differentiate into more mature tumor cells. Results of Piccirillo et al. showed that BMP4 induced glioblastoma differentiation in mice models of human glioblastoma [148]. Modulation of CSC signaling pathways has also shown the differentiation of CSCs in medulloblastoma [149]. In human breast cancer, Gupta et al. identified that potassium ionophore and salinomycin could induce epithelial differentiation of tumor cells and result in inhibition of tumor growth [150]. In addition, the effects of the inhibitor and agonist for SIRT1/2 on the inducing osteogenic differentiation indicated that SIRT1/2 had an important role in this process. Inducing differentiation of cancer cells may have potentially translational applications in the treatment of SCLC [6]. EMT plays a critical role in tumor formation and differentiation. EMT is involved in tumor metastasis and is highly correlated with tumor progression. Cancer cells undergo EMT to exhibit a high degree of plasticity, which many studies have begun to exploit therapeutically by forcing the transdifferentiation of EMTderived cancer cells into benign cells. Ishay-Ronen et al. showed that plasticity intrinsic to the EMT program could be exploited to divert cancer cells into becoming postmitotic adipocytes, thus preventing the metastases of cancer. A cocktail of rosiglitazone and BMP2 (a member of the transforming growth factor $\beta$ [TGF- $\beta$ ] superfamily) was shown to influence the cells with mesenchymal phenotype, but not epithelial phenotype [3]. The key step of adipocyte differentiation in tumors is the same as that in MSCs with activation of the transcription factor PPAR $\gamma$. The study refers to stem cells derived from the breast cancer microenvironment can be induced differentiation by and their impaired adipogenesis. The PPAR $\gamma$ agonist thiazolidinedione delays the invasive progression and induces adipose differentiation of ductal carcinoma in situ [3]. Adipose-derived stem cells could be induced into adipocytes by the PPAR $\gamma$ agonist thiazolidinedione, which was impaired by breast cancer microenvironment [151]. The adipocytes derived from breast cancer cells are truly functional adipocytes. They express adipocytespecific markers (such as C/EPB genes, PPAR $22, \mathrm{FABP} 4$ ) that show similar adipocyte metabolic and transcriptome characteristics of adipocytes and lack mesenchymal morphological features. The induced cells strongly expressed CEBP $\alpha$ and formed lipid droplets. Two FDA-approved drugs were used to treat animal xenografts from breast cancer cells. The two drugs are a combination of rosiglitazone, a PPAR inhibitor widely used to treat diabetes, and trametinib, a MEK inhibitor. Compared with the treatment drug trametinib alone, the combination treatment did not significantly inhibit tumor growth, but it significantly inhibited tumor invasion and metastasis. The combination treatment had no toxic effect on mice. Preclinical models further confirmed the effectiveness of this adipogenesis therapy. A high number of human adipocytes were detected in primary tumors treated with the combination of rosiglitazone and trametinib, and a significant decrease was found in tumor cells metastasized to the lung [3].

PARP inhibition can induce the transdifferentiation of white adipocytes to brown-like adipocytes, and the activity of PARP may be a determinant of the differentiation of these adipocyte lineages [152]. Olaparib, a potent PARP inhibitor used in clinical, can induce white adipocytes to transdifferentiate into brown/beige adipocytes with smaller lipid droplets. Olaparib can inhibit nuclear and cytosolic poly-ADP-ribose formation, induced $\mathrm{NAD}+/ \mathrm{NADH}$ ratio, and consequently enhanced SIRT1 and AMPK activity [152]. PARP inhibitors enhance the cytotoxic effects of antitumor drugs and radiotherapy and selectively kill tumor cells with homologous recombination deficiency, such as BRCA1 
or BRCA2 mutations $[153,154]$. Olaparib is the first small molecule PARP inhibitor compound approved by the FDA and EMA to enter the clinic in 2014 for the treatment of advanced-stage BRCA1/2-mutated ovarian cancers. In a phase III clinical trial of pancreatic cancer patients in 2019, Olaparib achieved positive results in progression-free survival $[154,155]$. Rucaparib is an inhibitor of PARP, and it disrupts DNA repair and replication pathways, leading to the selective killing of cancer cells with BRCA1/2 mutations [144]. In addition, the expression of S100A16 in human breast cancer tissues was higher than in the paired adjacent noncancerous tissues. S100A16 is a calcium-binding signaling protein, promotes adipogenesis, and involved in weight gain attenuation induced by dietary calcium. Enhanced adipogenesis with more lipid droplet density was clearly observed in 3T3-L1 preadipocytes with overexpression of S100A16 [156]. S100A16 promoted EMT by upregulating the transcription factors Notch1, ZEB1, and ZEB2, which had the capacities to directly repress the expression of epithelial markers E-cadherin and beta-catenin but increase mesenchymal markers $\mathrm{N}$-cadherin and vimentin [5]. All the results regarding differentiation therapy may hold great promise for new therapeutic strategies. Many targeted differentiation therapies for CSCs are currently undergoing preclinical and clinical research with the aim of reducing tumor recurrence and metastatic spread.

\section{Conclusions}

Adipocyte differentiation is a complex process, and a series of molecular and signaling pathways have been identified as involved in regulating adipocyte differentiation. MSCs, which are recruited from the vascular stroma of adipose tissue, provide the adipocyte precursors. Members of the BMP and Wnt families are key mediators of stem cell commitment to produce preadipocytes. In addition, exposure of growtharrested preadipocytes to differentiation inducers such as IGF1, glucocorticoid, and cAMP triggers DNA replication and reentry into mitotic clonal expansion, which involves a transcription factor cascade followed by the expression of adipocyte genes. Critical to these events are phosphorylation of the transcription factor $\mathrm{C} / \mathrm{EBP} \beta$ by MAP kinase and GSK $3 \beta$, and activated C/EBP $\beta$ then triggers transcription of $\operatorname{PPAR} \gamma$ and $\mathrm{C} / \mathrm{EBP} \alpha$, which in turn coordinately activate genes whose expression produces the adipocyte phenotype.

CSCs play an important fundamental role in tumor progression because of their tumorigenic properties, resistance to radiation and chemotherapy, invasiveness, and tendency to evade immune responses, which contribute to tumor recurrence. The difficulty of targeting CSCs lies in the intrinsic properties of these cells and the acquired phenotypes following therapeutic interventions. These characteristics underscore the importance of innovative treatment options. Cell differentiation is an important pathway in tumor transformation, and a better understanding of typical differentiation factors may open the door to new therapeutic strategies that regulate key differentiation pathways in cancer. Although the understanding of the process of adipocyte differentiation has improved over the past 20 years, many questions remain. For example, how can adipocyte differentiation be induced in vivo? How can the different differentiation directions of pluripotent stem cells be balanced? Can we avoid diseases by influencing the adipocyte differentiation of stem cells? Almost every important cellular signaling pathway has a positive or negative effect on adipocyte development, and some pathways exert both pro- and antiadipogenic effects depending on factors that are still poorly understood. Many targeted differentiation therapies for CSCs are currently undergoing preclinical and clinical research with the aim of reducing recurrence and metastatic spread. Current and future studies will provide strong evidence for solving various problems and focus on accurate targets for the treatment of adipocyte differentiation-related diseases. Studies about the molecular mechanism and regulatory proteins involved in adipocyte differentiation of MSCs may provide new therapeutic ideas and targets for clinical malignant tumor differentiation therapy.

\section{Abbreviations}

MSCs: $\quad$ Mesenchymal stem cells

CSCs: Cancer stem cells

PGCCs: $\quad$ Polyploid giant cancer cells

IBMX: 3-isobutyl-1-methylxanthine

EMT: $\quad$ Epithelial-to-mesenchymal transition

BRCA: Breast cancer sususceptibility gene

WDLPS: Well-differentiated liposarcoma

DDLPS: Dedifferentiated liposarcoma

BMP: $\quad$ Bone morphogenetic protein

C/EBPs: $\quad$ CCAAT enhancer-binding proteins

CHOP: $\quad$ C/EBP-homologous protein

CBP: $\quad$ Cyclic AMP response element-binding protein

FABP4: $\quad$ Fatty acid-binding protein 4

PPAR $\gamma$ : $\quad$ Peroxisome proliferator-activated receptor $\gamma$

PPRE: $\quad$ Peroxisome proliferator response element

PPFP: $\quad$ PPAR $\gamma$ fusion protein

PARP: $\quad$ Poly ADP-ribose polymerase

RXR: $\quad$ Retinoid X receptor

IGF1:

TGF:

TNF:

FGF:

MMP:

SMAD: Drosophila mothers against decapentaplegic protein

ERK: $\quad$ Extracellular regulated protein kinases

MAPK: $\quad$ Mitogen-activated protein kinase

MKP1: $\quad$ Mitogen-activated protein kinase phosphatase-1

JAK-STAT3: Janus kinase-signal transducer and activator of transcription 3

PI3K: $\quad$ Phosphoinositide 3-kinase

AKT/PKB: $\quad$ Protein kinase B

mTOR: $\quad$ Serine/threonine-protein kinase

KLF: Krüppel-like factors

$\mathrm{HH}$ : Hedgehog

HDAC: $\quad$ Histone deacetylase 


$\begin{array}{ll}\text { SREBP: } & \text { Sterol-regulatory element-binding proteins } \\ \text { Pref: } & \text { Preadipocyte factor } \\ \text { GLUT4: } & \text { Glucose transporter } 4 \\ \text { LSD1/KDM1: } & \text { Lysine specific demethylase 1 A } \\ \text { SIRT1: } & \text { sirtuin1 } \\ \text { sFRP: } & \text { Secreted frizzled-related protein } \\ \text { FOXO: } & \text { Forkhead box protein O } \\ \text { P300: } & \text { Histone acetyltransferase p300 } \\ \text { SETD: } & \text { SET domain-containing } \\ \text { HOX: } & \text { Homeotic genes } \\ \text { LncRNA: } & \text { Long noncoding RNA } \\ \text { Arp2/3: } & \text { Actin-related protein 2/3 } \\ \text { PARylation: } & \text { Poly-ADP-ribosylation } \\ \text { EIF: } & \text { Eukaryotic translation initiation factor } \\ \text { ROS: } & \text { Oxygen species } \\ \text { Atg: } & \text { Autophagy-related gene } \\ \text { EBF: } & \text { Transcription factor Coe } \\ \text { NCoR: } & \text { Nuclear receptor corepressor. }\end{array}$

\section{Conflicts of Interest}

The authors declare that there is no conflict of interest.

\section{Authors' Contributions}

SZ designed the study, contributed to manuscript writing, and approved the manuscript before submission. KZ, XY, and QZ collected and analyzed data and approved the manuscript before submission. ZL, FF, and HZ collected, analyzed, and interpreted data, and approved the manuscript before submission. MZ collected data, gave constructive comments on the manuscript, and approved the manuscript before submission. Kexin Zhang and Xudong Yang contributed equally to this work.

\section{Acknowledgments}

This work was supported in part by grants from the National Natural Science Foundation of China (81672426) and the foundation of committee on science and technology of Tianjin (17ZXMFSY00120 and 17YFZCSY00700).

\section{References}

[1] K. Sarjeant and J. M. Stephens, "Adipogenesis," Cold Spring Harbor Perspectives in Biology, vol. 4, no. 9, article a008417, 2012.

[2] M. Zeniou, L. Nguekeu-Zebaze, and F. Dantzer, "Therapeutic considerations of PARP in stem cell biology: relevance in cancer and beyond," Biochemical Pharmacology, vol. 167, pp. 107-115, 2019.

[3] D. Ishay-Ronen, M. Diepenbruck, R. K. R. Kalathur et al., "Gain Fat-Lose Metastasis: Converting Invasive Breast Cancer Cells into Adipocytes Inhibits Cancer Metastasis," Cancer Cell, vol. 35, no. 1, pp. 17-32.e6, 2019.

[4] G. B. Park, Y. H. Chung, J. H. Gong, D. H. Jin, and D. Kim, "GSK-3 $\beta$-mediated fatty acid synthesis enhances epithelial to mesenchymal transition of TLR4-activated colorectal cancer cells through regulation of TAp63," International Journal of Oncology, vol. 49, no. 5, pp. 2163-2172, 2016.
[5] W. Zhou, H. Pan, T. Xia et al., "Up-regulation of S100A16 expression promotes epithelial-mesenchymal transition via Notch1 pathway in breast cancer," Journal of Biomedical Science, vol. 21, no. 1, p. 97, 2014.

[6] Z. Zhang, Y. Zhou, H. Qian et al., "Stemness and inducing differentiation of small cell lung cancer NCI-H446 cells," Cell Death \& Disease, vol. 4, no. 5, article e633, 2013.

[7] P. Hallenborg, S. Feddersen, L. Madsen, and K. Kristiansen, "The tumor suppressors pRB and p53 as regulators of adipocyte differentiation and function," Expert Opinion on Therapeutic Targets, vol. 13, no. 2, pp. 235-246, 2008.

[8] U. Basu-Roy, E. Han, K. Rattanakorn et al., "PPAR $\gamma$ agonists promote differentiation of cancer stem cells by restraining YAP transcriptional activity," Oncotarget, vol. 7, no. 38, pp. 60954-60970, 2016.

[9] M. E. Dobson, E. Diallo-Krou, V. Grachtchouk et al., "Pioglitazone induces a proadipogenic antitumor response in mice with PAX8-PPARgamma fusion protein thyroid carcinoma," Endocrinology, vol. 152, no. 11, pp. 4455-4465, 2011.

[10] Y. J. Kim, D. B. Yu, M. Kim, and Y. L. Choi, "Adipogenesis induces growth inhibition of dedifferentiated liposarcoma," Cancer Science, vol. 110, no. 8, pp. 2676-2683, 2019.

[11] H. G. Linhart, K. Ishimura-Oka, F. DeMayo et al., "C/EBPalpha is required for differentiation of white, but not brown, adipose tissue," Proceedings of the National Academy of Sciences of the United States of America, vol. 98, no. 22, pp. 12532-12537, 2001.

[12] L. Fajas, "Adipogenesis: a cross-talk between cell proliferation and cell differentiation," Annals of Medicine, vol. 35, no. 2, pp. 79-85, 2009.

[13] Q. Q. Tang and M. D. Lane, "Adipogenesis: from stem cell to adipocyte," Annual Review of Biochemistry, vol. 81, no. 1, pp. 715-736, 2012.

[14] D. Moseti, A. Regassa, and W. K. Kim, "Molecular regulation of adipogenesis and potential anti-adipogenic bioactive molecules," International Journal of Molecular Sciences, vol. 17, no. 1, p. 124, 2016.

[15] Q. Q. Tang, T. C. Otto, and M. D. Lane, "Mitotic clonal expansion: a synchronous process required for adipogenesis," Proceedings of the National Academy of Sciences of the United States of America, vol. 100, no. 1, pp. 44-49, 2003.

[16] Y. C. Cho and C. R. Jefcoate, "PPAR?1 synthesis and adipogenesis in C3H10T1/2 cells depends on S-phase progression, but does not require mitotic clonal expansion," Journal of Cellular Biochemistry, vol. 91, no. 2, pp. 336-353, 2004.

[17] E. D. Rosen and O. A. MacDougald, "Adipocyte differentiation from the inside out," Nature Reviews. Molecular Cell Biology, vol. 7, no. 12, pp. 885-896, 2006.

[18] I. Takada, A. P. Kouzmenko, and S. Kato, "Wnt and PPAR $\gamma$ signaling in osteoblastogenesis and adipogenesis," Nature Reviews Rheumatology, vol. 5, no. 8, pp. 442-447, 2009.

[19] C. Y. Logan and R. Nusse, "The Wnt signaling pathway in development and disease," Annual Review of Cell and Developmental Biology, vol. 20, no. 1, pp. 781-810, 2004.

[20] C. N. Bennett, S. E. Ross, K. A. Longo et al., "Regulation of Wnt signaling during adipogenesis," The Journal of Biological Chemistry, vol. 277, no. 34, pp. 30998-31004, 2002.

[21] K. A. Longo, W. S. Wright, S. Kang et al., "Wnt10b inhibits development of white and brown adipose tissues," The Journal of Biological Chemistry, vol. 279, no. 34, pp. 3550335509, 2004. 
[22] Y. H. Tseng, A. J. Butte, E. Kokkotou et al., "Prediction of preadipocyte differentiation by gene expression reveals role of insulin receptor substrates and necdin," Nature Cell Biology, vol. 7, no. 6, pp. 601-611, 2005.

[23] Y. H. Tseng, K. M. Kriauciunas, E. Kokkotou, and C. R. Kahn, "Differential roles of insulin receptor substrates in brown adipocyte differentiation," Molecular and Cellular Biology, vol. 24, no. 5, pp. 1918-1929, 2004.

[24] A. Kanazawa, S. Tsukada, M. Kamiyama, T. Yanagimoto, M. Nakajima, and S. Maeda, "Wnt5b partially inhibits canonical Wnt/ $\beta$-catenin signaling pathway and promotes adipogenesis in 3T3-L1 preadipocytes," Biochemical and Biophysical Research Communications, vol. 330, no. 2, pp. 505-510, 2005.

[25] M. M. Cohen Jr., "The hedgehog signaling network," American Journal of Medical Genetics. Part A, vol. 123A, no. 1, pp. 5-28, 2003.

[26] M. Varjosalo and J. Taipale, "Hedgehog: functions and mechanisms," Genes \& Development, vol. 22, no. 18, pp. 24542472, 2008.

[27] A. W. James, P. Leucht, B. Levi et al., "Sonic hedgehog influences the balance of osteogenesis and adipogenesis in mouse adipose-derived stromal cells," Tissue Engineering Part A, vol. 16, no. 8, pp. 2605-2616, 2010.

[28] S. Spinella-Jaegle, G. Rawadi, S. Kawai et al., "Sonic hedgehog increases the commitment of pluripotent mesenchymal cells into the osteoblastic lineage and abolishes adipocytic differentiation," Journal of Cell Science, vol. 114, Part 11, pp. 2085-2094, 2001.

[29] W. Cousin, C. Fontaine, C. Dani, and P. Peraldi, "Hedgehog and adipogenesis: fat and fiction," Biochimie, vol. 89, no. 12, pp. 1447-1453, 2007.

[30] C. Ge, W. P. Cawthorn, Y. Li, G. Zhao, O. A. MacDougald, and R. T. Franceschi, "Reciprocal control of osteogenic and adipogenic differentiation by ERK/MAP kinase phosphorylation of Runx2 and PPAR $\gamma$ transcription factors," Journal of Cellular Physiology, vol. 231, no. 3, pp. 587-596, 2016.

[31] H. Sakaue, W. Ogawa, T. Nakamura, T. Mori, K. Nakamura, and M. Kasuga, "Role of MAPK phosphatase-1 (MKP-1) in adipocyte differentiation," The Journal of Biological Chemistry, vol. 279, no. 38, pp. 39951-39957, 2004.

[32] E. D. Rosen, C. J. Walkey, P. Puigserver, and B. M. Spiegelman, "Transcriptional regulation of adipogenesis," Genes \& Development, vol. 14, no. 11, pp. 1293-1307, 2000.

[33] P. Tontonoz, E. Hu, and B. M. Spiegelman, "Stimulation of adipogenesis in fibroblasts by PPAR gamma 2, a lipidactivated transcription factor," Cell, vol. 79, no. 7, pp. 11471156, 1994

[34] Q. Tong, G. Dalgin, H. Xu, C. N. Ting, J. M. Leiden, and G. S. Hotamisligil, "Function of GATA transcription factors in preadipocyte-adipocyte transition," Science, vol. 290, no. 5489, pp. 134-138, 2000.

[35] E. Mueller, S. Drori, A. Aiyer et al., "Genetic analysis of adipogenesis through peroxisome proliferator-activated receptor $\gamma$ isoforms," The Journal of Biological Chemistry, vol. 277, no. 44, pp. 41925-41930, 2002.

[36] D. Ren, T. N. Collingwood, E. J. Rebar, A. P. Wolffe, and H. S. Camp, "PPARgamma knockdown by engineered transcription factors: exogenous PPARgamma2 but not PPARgammal reactivates adipogenesis," Genes \& Development, vol. 16 , no. 1, pp. 27-32, 2002.
[37] J. Zhang, M. Fu, T. Cui et al., "Selective disruption of PPARgamma 2 impairs the development of adipose tissue and insulin sensitivity," Proceedings of the National Academy of Sciences of the United States of America, vol. 101, no. 29, pp. 10703-10708, 2004.

[38] S. R. Farmer, "Transcriptional control of adipocyte formation," Cell Metabolism, vol. 4, no. 4, pp. 263-273, 2006.

[39] R. J. Christy, K. H. Kaestner, D. E. Geiman, and M. D. Lane, "CCAAT/enhancer binding protein gene promoter: binding of nuclear factors during differentiation of 3T3-L1 preadipocytes," Proceedings of the National Academy of Sciences of the United States of America, vol. 88, no. 6, pp. 2593-2597, 1991.

[40] Y. Zuo, L. Qiang, and S. R. Farmer, "Activation of CCAA T/enhancer-binding protein (C/EBP) alpha expression by $\mathrm{C} / \mathrm{EBP}$ beta during adipogenesis requires a peroxisome proliferator-activated receptor-gamma-associated repression of HDAC1 at the C/ebp alpha gene promoter," The Journal of Biological Chemistry, vol. 281, no. 12, pp. 7960-7967, 2006.

[41] E. D. Rosen, C. H. Hsu, X. Wang et al., "C/EBPalpha induces adipogenesis through PPARgamma: a unified pathway," Genes \& Development, vol. 16, no. 1, pp. 22-26, 2002.

[42] Z. Wu, E. D. Rosen, R. Brun et al., "Cross-Regulation of $\mathrm{C} / \mathrm{EBP} \alpha$ and PPAR $\gamma$ Controls the Transcriptional Pathway of Adipogenesis and Insulin Sensitivity," Molecular Cell, vol. 3, no. 2, pp. 151-158, 1999.

[43] A. K. El-Jack, J. K. Hamm, P. F. Pilch, and S. R. Farmer, "Reconstitution of insulin-sensitive glucose transport in fibroblasts requires expression of both PPAR $\gamma$ and $\mathrm{C} / \mathrm{EBP} \alpha$," The Journal of Biological Chemistry, vol. 274, no. 12, pp. 7946-7951, 1999.

[44] H. Huang, T. J. Song, X. Li et al., "BMP signaling pathway is required for commitment of $\mathrm{C} 3 \mathrm{H} 10 \mathrm{~T} 1 / 2$ pluripotent stem cells to the adipocyte lineage," Proceedings of the National Academy of Sciences of the United States of America, vol. 106, no. 31, pp. 12670-12675, 2009.

[45] S. E. Wheeler and N. Y. Lee, "Emerging roles of transforming growth factor $\beta$ signaling in diabetic retinopathy," Journal of Cellular Physiology, vol. 232, no. 3, pp. 486-489, 2017.

[46] M. Kawai and C. J. Rosen, "The IGF-I regulatory system and its impact on skeletal and energy homeostasis," Journal of Cellular Biochemistry, vol. 111, no. 1, pp. 14-19, 2010.

[47] C. B. Sullivan, R. M. Porter, C. H. Evans et al., "TNF $\alpha$ and IL$1 \beta$ influence the differentiation and migration of murine MSCs independently of the NF- $\kappa \mathrm{B}$ pathway," Stem Cell Research \& Therapy, vol. 5, no. 4, p. 104, 2014.

[48] D. Bauters, I. Scroyen, M. van Hul, and H. R. Lijnen, "Gelatinase A (MMP-2) promotes murine adipogenesis," Biochimica et Biophysica Acta, vol. 1850, no. 7, pp. 1449-1456, 2015.

[49] S. Le Blanc, M. Simann, F. Jakob, N. Schütze, and T. Schilling, "Fibroblast growth factors 1 and 2 inhibit adipogenesis of human bone marrow stromal cells in 3D collagen gels," Experimental Cell Research, vol. 338, no. 2, pp. 136-148, 2015.

[50] Q. Q. Tang, T. C. Otto, and M. D. Lane, "Commitment of C3H10T1/2 pluripotent stem cells to the adipocyte lineage," Proceedings of the National Academy of Sciences of the United States of America, vol. 101, no. 26, pp. 9607-9611, 2004.

[51] J. Massague, J. Seoane, and D. Wotton, "Smad transcription factors," Genes \& Development, vol. 19, no. 23, pp. 27832810, 2005. 
[52] L. Choy and R. Derynck, "Transforming growth factor-beta inhibits adipocyte differentiation by $\mathrm{Smad} 3$ interacting with CCAAT/enhancer-binding protein (C/EBP) and repressing C/EBP transactivation function," The Journal of Biological Chemistry, vol. 278, no. 11, pp. 9609-9619, 2003.

[53] L. Choy, J. Skillington, and R. Derynck, "Roles of autocrine TGF-beta receptor and Smad signaling in adipocyte differentiation," The Journal of Cell Biology, vol. 149, no. 3, pp. 667$682,2000$.

[54] N. I. zur Nieden, G. Kempka, D. E. Rancourt, and H.-J. Ahr, "Induction of chondro-, osteo- and adipogenesis in embryonic stem cells by bone morphogenetic protein-2: effect of cofactors on differentiating lineages," BMC Developmental Biology, vol. 5, no. 1, p. 1, 2005.

[55] E. A. Wang, D. I. Israel, S. Kelly, and D. P. Luxenberg, "Bone morphogenetic protein-2 causes commitment and differentiation in C3Hl0T1/2 and 3T3 cells," Growth Factors, vol. 9, no. 1, pp. 57-71, 2009.

[56] T. Mori, H. Sakaue, H. Iguchi et al., "Role of Krüppel-like factor 15 (KLF15) in transcriptional regulation of adipogenesis," The Journal of Biological Chemistry, vol. 280, no. 13, pp. 12867-12875, 2005.

[57] M. K. Jang, S. Lee, and M. H. Jung, "RNA-Seq analysis reveals a negative role of KLF16 in adipogenesis," PLoS One, vol. 11, no. 9, article e0162238, 2016.

[58] M. Asada, A. Rauch, H. Shimizu et al., "DNA bindingdependent glucocorticoid receptor activity promotes adipogenesis via Krüppel-like factor 15 gene expression," Laboratory Investigation, vol. 91, no. 2, pp. 203-215, 2011.

[59] Y. Oishi, I. Manabe, K. Tobe et al., "Krüppel-like transcription factor KLF5 is a key regulator of adipocyte differentiation," Cell Metabolism, vol. 1, no. 1, pp. 27-39, 2005.

[60] H. Pei, Y. Yao, Y. Yang, K. Liao, and J. R. Wu, "Kruppel-like factor KLF9 regulates PPAR $\gamma$ transactivation at the middle stage of adipogenesis," Cell Death and Differentiation, vol. 18, no. 2, pp. 315-327, 2011.

[61] Z. Chen, J. I. Torrens, A. Anand, B. M. Spiegelman, and J. M. Friedman, "Krox20 stimulates adipogenesis via $\mathrm{C} / \mathrm{EBP} \beta$ dependent and -independent mechanisms," Cell Metabolism, vol. 1, no. 2, pp. 93-106, 2005.

[62] D. Li, S. Yea, S. Li et al., "Krüppel-like factor-6 promotes preadipocyte differentiation through histone deacetylase 3dependent repression of DLK1," The Journal of Biological Chemistry, vol. 280, no. 29, pp. 26941-26952, 2005.

[63] S. S. Banerjee, M. W. Feinberg, M. Watanabe et al., "The Krüppel-like factor KLF2 inhibits peroxisome proliferatoractivated Receptor- $\gamma$ expression and adipogenesis," The Journal of Biological Chemistry, vol. 278, no. 4, pp. 2581-2584, 2003.

[64] J. Yun, H. Jin, Y. Cao et al., "RNA-Seq analysis reveals a positive role of HTR2A in adipogenesis in Yan Yellow Cattle," International Journal of Molecular Sciences, vol. 19, no. 6, article 1760, 2018.

[65] N. Sue, B. H. A. Jack, S. A. Eaton et al., "Targeted disruption of the basic Krüppel-Like factor gene (Klf3) reveals a role in adipogenesis," Molecular and Cellular Biology, vol. 28, no. 12, pp. 3967-3978, 2008.

[66] W. Yang, C. Yang, J. Luo, Y. Wei, W. Wang, and Y. Zhong, "Adiponectin promotes preadipocyte differentiation via the PPAR $\gamma$ pathway," Molecular Medicine Reports, vol. 17, no. 1 , pp. $428-435,2018$.
[67] J. M. Stephens, R. F. Morrison, and P. F. Pilch, "The expression and regulation of STATs during 3T3-L1 adipocyte differentiation," The Journal of Biological Chemistry, vol. 271, no. 18, pp. 10441-10444, 1996.

[68] Z. E. Floyd and J. M. Stephens, "STAT5A promotes adipogenesis in nonprecursor cells and associates with the glucocorticoid receptor during adipocyte differentiation," Diabetes, vol. 52, no. 2, pp. 308-314, 2003.

[69] P. Gao, Y. Zhang, Y. Liu et al., "Signal transducer and activator of transcription 5B (STAT5B) modulates adipocyte differentiation via MOF," Cellular Signalling, vol. 27, no. 12, pp. 2434-2443, 2015.

[70] D. Annamalai and N. A. Clipstone, "Prostaglandin F2 $\alpha$ inhibits adipogenesis via an autocrine-mediated interleukin11/glycoprotein 130/STAT1-dependent signaling cascade," Journal of Cellular Biochemistry, vol. 115, no. 7, pp. 13081321, 2014.

[71] X. Hu, Y. Zhou, Y. Yang et al., "Identification of zinc finger protein Bcl6 as a novel regulator of early adipose commitment," Open Biology, vol. 6, no. 6, article 160065, 2016.

[72] M. A. Meraz, J. M. White, K. C. F. Sheehan et al., “Targeted Disruption of the Stat1 Gene in Mice Reveals Unexpected Physiologic Specificity in the JAK -STAT Signaling Pathway," Cell, vol. 84, no. 3, pp. 431-442, 1996.

[73] Y. Yuan, Y. Xi, J. Chen et al., "STAT3 stimulates adipogenic stem cell proliferation and cooperates with HMGA2 during the early stage of differentiation to promote adipogenesis," Biochemical and Biophysical Research Communications, vol. 482, no. 4, pp. 1360-1366, 2017.

[74] E. R. Cernkovich, J. Deng, M. C. Bond, T. P. Combs, and J. B. Harp, "Adipose-specific disruption of signal transducer and activator of transcription 3 increases body weight and adiposity," Endocrinology, vol. 149, no. 4, pp. 1581-1590, 2008.

[75] S. Teglund, C. McKay, E. Schuetz et al., "Stat5a and Stat5b proteins have essential and nonessential, or redundant, roles in cytokine responses," Cell, vol. 93, no. 5, pp. 841-850, 1998.

[76] Y. Zhou, J. Peng, and S. Jiang, "Role of histone acetyltransferases and histone deacetylases in adipocyte differentiation and adipogenesis," European Journal of Cell Biology, vol. 93, no. 4, pp. 170-177, 2014.

[77] C. M. Bäckesjö, Y. Li, U. Lindgren, and L. A. Haldosén, “Activation of Sirt1 decreases adipocyte formation during osteoblast differentiation of mesenchymal stem cells," Journal of Bone and Mineral Research, vol. 21, no. 7, pp. 993-1002, 2006.

[78] Y. Zhou, T. Song, J. Peng et al., "SIRT1 suppresses adipogenesis by activating $\mathrm{Wnt} / \beta$-catenin signaling in vivo and in vitro," Oncotarget, vol. 7, no. 47, pp. 77707-77720, 2016.

[79] X. J. Yang and E. Seto, "Lysine acetylation: codified crosstalk with other posttranslational modifications," Molecular Cell, vol. 31, no. 4, pp. 449-461, 2008.

[80] J. Chen, Y. Lu, M. Tian, and Q. Huang, "Molecular mechanisms of FOXO1 in adipocyte differentiation," Journal of Molecular Endocrinology, vol. 62, no. 3, pp. R239-R253, 2019.

[81] E. Jing, S. Gesta, and C. R. Kahn, "SIRT2 regulates adipocyte differentiation through FoxO1 acetylation/deacetylation," Cell Metabolism, vol. 6, no. 2, pp. 105-114, 2007.

[82] R. M. Evans, G. D. Barish, and Y. X. Wang, "PPARs and the complex journey to obesity," Nature Medicine, vol. 10, no. 4 , pp. $355-361,2004$. 
[83] J. E. Dominy and P. Puigserver, "Nuclear FoxO1 inflames insulin resistance," The EMBO Journal, vol. 29, no. 24, pp. 4068-4069, 2010.

[84] L. Qiang, L. Wang, N. Kon et al., "Brown remodeling of white adipose tissue by SirT1-dependent deacetylation of Ppary," Cell, vol. 150, no. 3, pp. 620-632, 2012.

[85] M. M. Musri, M. C. Carmona, F. A. Hanzu, P. Kaliman, R. Gomis, and M. Párrizas, "Histone demethylase LSD1 regulates adipogenesis," The Journal of Biological Chemistry, vol. 285, no. 39, pp. 30034-30041, 2010.

[86] K. Wakabayashi, M. Okamura, S. Tsutsumi et al., "The peroxisome proliferator-activated receptor gamma/retinoid $\mathrm{X}$ receptor alpha heterodimer targets the histone modification enzyme PR-Set7/Setd8 gene and regulates adipogenesis through a positive feedback loop," Molecular and Cellular Biology, vol. 29, no. 13, pp. 3544-3555, 2009.

[87] L. Wang, Q. Jin, J. E. Lee, I. H. Su, and K. Ge, "Histone H3K27 methyltransferase Ezh2 represses Wnt genes to facilitate adipogenesis," Proceedings of the National Academy of Sciences of the United States of America, vol. 107, no. 16, pp. 73177322, 2010.

[88] Z. Fan, T. Yamaza, J. S. Lee et al., "BCOR regulates mesenchymal stem cell function by epigenetic mechanisms," Nature Cell Biology, vol. 11, no. 8, pp. 1002-1009, 2009.

[89] J. Chen, Y. Liu, S. Lu et al., “The role and possible mechanism of lncRNA U90926 in modulating 3T3-L1 preadipocyte differentiation," International Journal of Obesity, vol. 41, no. 2, pp. 299-308, 2017.

[90] K. Kajimoto, H. Naraba, and N. Iwai, "MicroRNA and 3T3L1 pre-adipocyte differentiation," RNA, vol. 12, no. 9, pp. 1626-1632, 2006.

[91] H. Xie, B. Lim, and H. F. Lodish, "MicroRNAs induced during adipogenesis that accelerate fat cell development are downregulated in obesity," Diabetes, vol. 58, no. 5, pp. 1050-1057, 2009.

[92] J. A. Kennell, I. Gerin, O. A. MacDougald, and K. M. Cadigan, "The microRNA miR-8 is a conserved negative regulator of Wnt signaling," Proceedings of the National Academy of Sciences of the United States of America, vol. 105, no. 40, pp. 15417-15422, 2008.

[93] D. Hamam, D. Ali, M. Kassem, A. Aldahmash, and N. M. Alajez, "microRNAs as regulators of adipogenic differentiation of mesenchymal stem cells," Stem Cells and Development, vol. 24, no. 4, pp. 417-425, 2015.

[94] E. K. Lee, M. J. Lee, K. Abdelmohsen et al., "miR-130 suppresses adipogenesis by inhibiting peroxisome proliferatoractivated receptor gamma expression," Molecular and Cellular Biology, vol. 31, no. 4, pp. 626-638, 2011.

[95] Z. Yuan, Q. Li, S. Luo et al., "PPAR $\gamma$; and Wnt signaling in adipogenic and osteogenic differentiation of mesenchymal stem cells," Current Stem Cell Research \& Therapy, vol. 11, no. 3, pp. 216-225, 2016.

[96] E. Eklund, "The role of Hox proteins in leukemogenesis: insights into key regulatory events in hematopoiesis," Critical Reviews in Oncogenesis, vol. 16, no. 1-2, pp. 65-76, 2011.

[97] X. X. Zhu, Y. W. Yan, D. Chen et al., "Long non-coding RNA HoxA-AS3 interacts with EZH2 to regulate lineage commitment of mesenchymal stem cells," Oncotarget, vol. 7, no. 39, pp. 63561-63570, 2016.

[98] Y. Huang, Y. Zheng, C. Jin, X. Li, L. Jia, and W. Li, "Long Non-coding RNA H19 Inhibits Adipocyte Differentiation of
Bone Marrow Mesenchymal Stem Cells through Epigenetic Modulation of Histone Deacetylases," Scientific Reports, vol. 6, no. 1, article 28897, 2016.

[99] M. Li, X. Sun, H. Cai et al., "Long non-coding RNA ADNCR suppresses adipogenic differentiation by targeting miR-204," Biochimica et Biophysica Acta, vol. 1859, no. 7, pp. 871-882, 2016.

[100] R. Gernapudi, B. Wolfson, Y. Zhang et al., "MicroRNA 140 promotes expression of long noncoding RNA NEAT1 in adipogenesis," Molecular and Cellular Biology, vol. 36, no. 1, pp. 30-38, 2016.

[101] L. Mi, X. Y. Zhao, S. Li, G. Yang, and J. D. Lin, “Conserved function of the long noncoding RNA Blnc1 in brown adipocyte differentiation," Molecular Metabolism, vol. 6, no. 1, pp. 101-110, 2017.

[102] E. Zhu, J. Zhang, Y. Li, H. Yuan, J. Zhou, and B. Wang, "Long noncoding RNAPlnclcontrols adipocyte differentiation by regulating peroxisome proliferator-activated receptor $\gamma$," The FASEB Journal, vol. 33, no. 2, pp. 2396-2408, 2018.

[103] M. Wang and R. J. Kaufman, "The impact of the endoplasmic reticulum protein-folding environment on cancer development," Nature Reviews Cancer, vol. 14, no. 9, pp. 581-597, 2014.

[104] C. E. Lowe, R. J. Dennis, U. Obi, S. O'Rahilly, and J. J. Rochford, "Investigating the involvement of the ATF6 $\alpha$ pathway of the unfolded protein response in adipogenesis," International Journal of Obesity, vol. 36, no. 9, pp. 1248-1251, 2012.

[105] T. P. T. Pham, J. Kwon, and J. Shin, "Berberine exerts antiadipogenic activity through up-regulation of C/EBP inhibitors, CHOP and DEC2," Biochemical and Biophysical Research Communications, vol. 413, no. 2, pp. 376-382, 2011.

[106] J. Han, R. Murthy, B. Wood et al., "ER stress signalling through eIF $2 \alpha$ and CHOP, but not IRE $1 \alpha$, attenuates adipogenesis in mice," Diabetologia, vol. 56, no. 4, pp. 911-924, 2013.

[107] F. Atashi, A. Modarressi, and M. S. Pepper, "The role of reactive oxygen species in mesenchymal stem cell adipogenic and osteogenic differentiation: a review," Stem Cells and Development, vol. 24, no. 10, pp. 1150-1163, 2015.

[108] T. Lonergan, C. Brenner, and B. Bavister, "Differentiationrelated changes in mitochondrial properties as indicators of stem cell competence," Journal of Cellular Physiology, vol. 208, no. 1, pp. 149-153, 2006.

[109] A. H. Kramer, R. Kadye, P. S. Houseman, and E. Prinsloo, "Mitochondrial STAT3 and reactive oxygen species: a fulcrum of adipogenesis?," Jakstat, vol. 4, no. 2, article e1084084, 2015.

[110] K. Schröder, K. Wandzioch, I. Helmcke, and R. P. Brandes, "Nox4 acts as a switch between differentiation and proliferation in preadipocytes," Arteriosclerosis, Thrombosis, and Vascular Biology, vol. 29, no. 2, pp. 239-245, 2009.

[111] S. Hwang, J. W. Byun, J. S. Yoon, and E. J. Lee, "Inhibitory effects of $\alpha$-Lipoic acid on oxidative stress-induced adipogenesis in orbital fibroblasts from patients with graves ophthalmopathy," Medicine (Baltimore), vol. 95, no. 2, article e2497, 2016.

[112] K. V. Tormos, E. Anso, R. B. Hamanaka et al., "Mitochondrial complex III ROS regulate adipocyte differentiation," Cell Metabolism, vol. 14, no. 4, pp. 537-544, 2011.

[113] S. Furukawa, T. Fujita, M. Shimabukuro et al., "Increased oxidative stress in obesity and its impact on metabolic 
syndrome," The Journal of Clinical Investigation, vol. 114, no. 12, pp. 1752-1761, 2004.

[114] H. Yan, E. Aziz, G. Shillabeer et al., "Nitric oxide promotes differentiation of rat white preadipocytes in culture," Journal of Lipid Research, vol. 43, no. 12, pp. 2123-2129, 2002.

[115] R. Singh, S. Kaushik, Y. Wang et al., "Autophagy regulates lipid metabolism," Nature, vol. 458, no. 7242, pp. 11311135, 2009.

[116] R. Baerga, Y. Zhang, P. H. Chen, S. Goldman, and S. V. Jin, "Targeted deletion of autophagy-related 5 (atg5) impairs adipogenesis in a cellular model and in mice," Autophagy, vol. 5, no. 8, pp. 1118-1130, 2014.

[117] C. Zhang, Y. He, M. Okutsu et al., "Autophagy is involved in adipogenic differentiation by repressesing proteasomedependent PPAR $\gamma 2$ degradation," American Journal of Physiology. Endocrinology and Metabolism, vol. 305, no. 4, pp. E530-E539, 2013.

[118] Y. Zhang, S. Goldman, R. Baerga, Y. Zhao, M. Komatsu, and S. Jin, "Adipose-specific deletion of autophagy-related gene 7 (atg7) in mice reveals a role in adipogenesis," Proceedings of the National Academy of Sciences of the United States of America, vol. 106, no. 47, pp. 19860-19865, 2009.

[119] L. Guo, J. X. Huang, Y. Liu et al., "Transactivation of Atg4b by C/EBP $\beta$ promotes autophagy to facilitate adipogenesis," Molecular and Cellular Biology, vol. 33, no. 16, pp. 31803190, 2013.

[120] J. Wu, X. Deng, J. Gao et al., "Autophagy mediates the secretion of macrophage migration inhibitory factor from cardiomyocytes upon serum-starvation," Science China. Life Sciences, vol. 62, no. 8, pp. 1038-1046, 2019.

[121] J. R. Hahm, M. Ahmed, and D. R. Kim, "RKIP phosphorylation-dependent ERK1 activation stimulates adipogenic lipid accumulation in 3T3-L1 preadipocytes overexpressing LC3," Biochemical and Biophysical Research Communications, vol. 478, no. 1, pp. 12-17, 2016.

[122] H. Li, Y. Cheng, W. Wu et al., "SRSF10 regulates alternative splicing and is required for adipocyte differentiation," Molecular and Cellular Biology, vol. 34, no. 12, pp. 2198-2207, 2014.

[123] M. E. Huot, G. Vogel, A. Zabarauskas et al., "The Sam68 STAR RNA-binding protein regulates mTOR alternative splicing during adipogenesis," Molecular Cell, vol. 46, no. 2, pp. 187-199, 2012.

[124] B. MEI, L. ZHAO, L. CHEN, and H. S. SUL, "Only the large soluble form of preadipocyte factor-1 (Pref-1), but not the small soluble and membrane forms, inhibits adipocyte differentiation: role of alternative splicing," The Biochemical Journal, vol. 364, no. 1, Part 1, pp. 137-144, 2002.

[125] R. McBeath, D. M. Pirone, C. M. Nelson, K. Bhadriraju, and C. S. Chen, "Cell shape, cytoskeletal tension, and RhoA regulate stem cell lineage commitment," Developmental Cell, vol. 6, no. 4, pp. 483-495, 2004.

[126] H. Nobusue, N. Onishi, T. Shimizu et al., "Regulation of MKL1 via actin cytoskeleton dynamics drives adipocyte differentiation," Nature Communications, vol. 5, no. 1, article 3368,2014

[127] B. Sen, Z. Xie, N. Case et al., "mTORC2 regulates mechanically induced cytoskeletal reorganization and lineage selection in marrow-derived mesenchymal stem cells," Journal of Bone and Mineral Research, vol. 29, no. 1, pp. 78-89, 2014.
[128] W. Yang, S. Thein, C. Y. Lim et al., "Arp2/3 complex regulates adipogenesis by controlling cortical actin remodelling," The Biochemical Journal, vol. 464, no. 2, pp. 179-192, 2014.

[129] L. V. Nguyen, R. Vanner, P. Dirks, and C. J. Eaves, "Cancer stem cells: an evolving concept," Nature Reviews Cancer, vol. 12, no. 2, pp. 133-143, 2012.

[130] A. Kreso and J. E. Dick, "Evolution of the cancer stem cell model," Cell Stem Cell, vol. 14, no. 3, pp. 275-291, 2014.

[131] W. Chen, J. Dong, J. Haiech, M. C. Kilhoffer, and M. Zeniou, "Cancer stem cell quiescence and plasticity as major challenges in cancer therapy," Stem Cells International, vol. 2016, Article ID 1740936, 16 pages, 2016.

[132] D. Contador, F. Ezquer, M. Espinosa et al., "Dexamethasone and rosiglitazone are sufficient and necessary for producing functional adipocytes from mesenchymal stem cells," Experimental Biology and Medicine (Maywood, N.J.), vol. 240, no. 9, pp. 1235-1246, 2015.

[133] S. Zhang, I. Mercado-Uribe, Z. Xing, B. Sun, J. Kuang, and J. Liu, "Generation of cancer stem-like cells through the formation of polyploid giant cancer cells," Oncogene, vol. 33, no. 1, pp. 116-128, 2014.

[134] Y. Liu, R. Zhang, J. Xin et al., "Identification of S100A16 as a novel adipogenesis promoting factor in 3T3-L1 cells," Endocrinology, vol. 152, no. 3, pp. 903-911, 2011.

[135] R. Virchow, "The Huxley lecture on recent advances in science and their bearing on medicine and surgery: delivered at the opening of the Charing Cross Hospital Medical School on October 3rd," British Medical Journal, vol. 2, no. 1971, pp. 1021-1028, 1898.

[136] Y. Yao, M. Suraokar, B. G. Darnay et al., "BSTA promotes mTORC2-mediated phosphorylation of Akt1 to suppress expression of FoxC2 and stimulate adipocyte differentiation," Science Signaling, vol. 6, no. 257, p. ra2, 2013.

[137] S. Almozyan, D. Colak, F. Mansour et al., "PD-L1 promotes OCT4 and Nanog expression in breast cancer stem cells by sustaining PI3K/AKT pathway activation," International Journal of Cancer, vol. 141, no. 7, pp. 1402-1412, 2017.

[138] M. Majumder, X. Xin, L. Liu et al., "COX-2 induces breast cancer stem cells via EP4/PI3K/AKT/NOTCH/WNT axis," Stem Cells, vol. 34, no. 9, pp. 2290-2305, 2016.

[139] M. Zhu, W. Li, Y. Lu et al., "HBx drives alpha fetoprotein expression to promote initiation of liver cancer stem cells through activating PI3K/AKT signal pathway," International Journal of Cancer, vol. 140, no. 6, pp. 1346-1355, 2017.

[140] J. Chen, R. Shao, F. Li et al., "PI3K/Akt/mTOR pathway dual inhibitor BEZ235 suppresses the stemness of colon cancer stem cells," Clinical and Experimental Pharmacology \& Physiology, vol. 42, no. 12, pp. 1317-1326, 2015.

[141] V. J. Heath, D. A. F. Gillespie, and D. H. Crouch, "Inhibition of the terminal stages of adipocyte differentiation by cMyc," Experimental Cell Research, vol. 254, no. 1, pp. 91-98, 2000.

[142] F. Fei, J. Qu, K. Liu et al., “The subcellular location of cyclin B1 and CDC25 associated with the formation of polyploid giant cancer cells and their clinicopathological significance," Laboratory Investigation, vol. 99, no. 4, pp. 483-498, 2019.

[143] M. Szanto and P. Bai, "The role of ADP-ribose metabolism in metabolic regulation, adipose tissue differentiation, and metabolism," Genes \& Development, vol. 34, no. 5-6, pp. 321-340, 2020.

[144] K. Y. Lin and W. L. Kraus, "PARP inhibitors for cancer therapy," Cell, vol. 169, no. 2, p. 183, 2017. 
[145] P. Bai, S. M. Houten, A. Huber et al., "Poly(ADP-ribose) polymerase-2 [corrected] controls adipocyte differentiation and adipose tissue function through the regulation of the activity of the retinoid $\mathrm{X}$ receptor/peroxisome proliferatoractivated receptor-gamma [corrected] heterodimer," The Journal of Biological Chemistry, vol. 282, no. 52, pp. 3773837746, 2007.

[146] N. Y. Frank, T. Schatton, and M. H. Frank, "The therapeutic promise of the cancer stem cell concept," The Journal of Clinical Investigation, vol. 120, no. 1, pp. 41-50, 2010.

[147] G. B. Pierce, "The cancer cell and its control by the embryo Rous-Whipple Award lecture," The American Journal of Pathology, vol. 113, no. 1, pp. 117-124, 1983.

[148] S. G. M. Piccirillo, B. A. Reynolds, N. Zanetti et al., "Bone morphogenetic proteins inhibit the tumorigenic potential of human brain tumour-initiating cells," Nature, vol. 444, no. 7120, pp. 761-765, 2006.

[149] X. Fan, W. Matsui, L. Khaki et al., "Notch pathway inhibition depletes stem-like cells and blocks engraftment in embryonal brain tumors," Cancer Research, vol. 66, no. 15, pp. 74457452, 2006.

[150] P. B. Gupta, T. T. onder, G. Jiang et al., "Identification of selective inhibitors of cancer stem cells by high-throughput screening," Cell, vol. 138, no. 4, pp. 645-659, 2009.

[151] F. Rey, E. Lesma, D. Massihnia et al., "Adipose-derived stem cells from fat tissue of breast cancer microenvironment present altered adipogenic differentiation capabilities," Stem Cells International, vol. 2019, Article ID 1480314, 15 pages, 2019.

[152] L. Nagy, B. Rauch, N. Balla et al., "Olaparib induces browning of in vitro cultures of human primary white adipocytes," Biochemical Pharmacology, vol. 167, pp. 76-85, 2019.

[153] B. A. Gibson and W. L. Kraus, "New insights into the molecular and cellular functions of poly(ADP-ribose) and PARPs," Nature Reviews Molecular Cell Biology, vol. 13, no. 7, pp. 411424, 2012.

[154] P. G. Pilié, C. M. Gay, L. A. Byers, M. J. O'Connor, and T. A. Yap, "PARP inhibitors: extending benefit BeyondBRCAMutant cancers," Clinical Cancer Research, vol. 25, no. 13, pp. 3759-3771, 2019.

[155] C. J. Lord and A. Ashworth, "PARP inhibitors: synthetic lethality in the clinic," Science, vol. 355, no. 6330, pp. 11521158, 2017.

[156] R. Zhang, W. Zhu, X. du et al., "S100A16 mediation of weight gain attenuation induced by dietary calcium," Metabolism, vol. 61, no. 2, pp. 157-163, 2012. 